\title{
The $\left\{\mathrm{FeO}_{2}\right\}^{8}$ intermediate of the TxtE nitration
}

\section{pathway resists reduction, facilitating its reaction}

\section{with nitric oxide}

Christopher P. Martin, ${ }^{1}$ Manyun Chen, ${ }^{2}$ Maria F. Martinez, ${ }^{1}$ Rosemary Loria, ${ }^{3}$ Yousong Ding, ${ }^{2 *}$ Jonathan D. Caranto. ${ }^{1 *}$

${ }^{1}$ Department of Chemistry, University of Central Florida, 4111 Libra Dr., Room 255,

Orlando, FL 32816

${ }^{2}$ Department of Medicinal Chemistry, Center for Natural Products, Drug Discovery and

Development, University of Florida, 1345 Center Dr., Room P6-27, Gainesville, FL 32610

${ }^{3}$ Department of Plant Pathology, University of Florida, 2550 Hull Road, PO Box 110680,

Gainesville, FL 32611

KEYWORDS

Nitric oxide, metalloenzyme, nitration, natural product, Streptomyces. 


\section{Abstract}

TxtE is a cytochome P450 (CYP) homolog that mediates a nitric oxide (NO)-dependent direct nitration of L-tryptophan (L-Trp) to form 4-nitrotryptophan (4-NO2-L-Trp). This nitrated product is a precursor for thaxtomin A, a virulence factor produced by plant-pathogenic bacteria that causes the disease potato scab. A recent study provided the first characterization of intermediates along the TxtE nitration pathway. ${ }^{1}$ The authors' accumulated evidence supported a mechanism in which $\mathrm{O}_{2}$ binds to $\mathrm{Fe}^{\mathrm{II}} \mathrm{TxtE}$ to form an $\left\{\mathrm{FeO}_{2}\right\}^{8}$ intermediate, which subsequently reacted with NO to ultimately form $\mathrm{Fe}^{\mathrm{III}} \mathrm{TxtE}$ and 4- $\mathrm{NO}_{2}-\mathrm{L}-\mathrm{Trp}$. Typical CYP mechanisms reduce and protonate the $\left\{\mathrm{FeO}_{2}\right\}^{8}$ intermediate to form a ferric-hydroperoxo species (Fe $\mathrm{FII}^{\mathrm{II}} \mathrm{OOH}$ ) en route to formation of the active oxidant compound I. The previously reported lack of hydroxylated tryptophan resulting from TxtE turnover suggests that the TxtE cycle must stall at the $\left\{\mathrm{FeO}_{2}\right\}^{8}$ intermediate to avoid hydroxylation. Here we present LC-MS experiments showing suggesting that TxtE can hydroxylate L-Trp by the peroxide shunt but not via reduction of the $\left\{\mathrm{FeO}_{2}\right\}^{8}$ intermediate. Comparison of stopped-flow time courses in the presence and absence of excess reducing equivalents and common CYP electron transfer partners shown no spectral or kinetic evidence for reduction of the $\left\{\mathrm{FeO}_{2}\right\}^{8}$ intermediate. Furthermore, the electron coupling efficiency of TB14-a self-sufficient TxtE variant with C-terminal reductase domain-to form 4- $\mathrm{NO}_{2}$-L-Trp exhibits a 3\% electron coupling efficiency when it is loaded with one reducing equivalent. This efficiency increases by 2-fold when TB14 is loaded with two or four reducing equivalents. This observation provides further evidence for our key conclusion that the $\mathrm{TxtE}\left\{\mathrm{FeO}_{2}\right\}^{8}$ intermediate resists reduction. The resistance of the $\left\{\mathrm{FeO}_{2}\right\}^{8}$ intermediate to reduction is a key feature of TxtE, enabling reaction with NO and efficient nitration turnover. 


\section{Introduction}

Cytochrome P450s (CYPs) are thiolate-ligated heme enzymes that are widespread amongst all kingdoms of life, with over 300,000 CYP sequences identified. ${ }^{2}$ Most CYPs exhibit monooxygenase or dioxygenase activities. However, a diverse range of chemistries have been observed, including ring expansions, nitrene transfers, nitrations, and both aerobic and anaerobic decomposition of explosives. ${ }^{3-7}$ Protein engineering efforts have introduced "new-to-Nature” activities including carbene transfer, fluorination, and hydroboration chemistries. ${ }^{8-12}$ The mechanisms of canonical CYP activities, especially of those catalyzing monooxygenase activity, have been intensely studied. However, less is understood about the mechanisms of CYP activities involving nitrogen, such as nitration.

We are particularly interested in TxtE, a CYP homolog that catalyzes a direct nitration of Ltryptophan (L-Trp) to produce 4-nitro-L-tryptophan (4-NO2-L-Trp) using nitric oxide (NO) and $\mathrm{O}_{2}$ as co-substrates. This enzyme was discovered in the biosynthetic pathway for thaxtominsvirulence factors of the tuber disease, scab-in Streptomyces scabies. ${ }^{13-17}$ Scab virulence factors including genes for thaxtomin biosynthesis have since been found in other plant-pathogenic Streptomyces species. ${ }^{18-19}$ Thaxtomin A, specifically, inhibits cellulose production. ${ }^{20}$ The diketopiperazine core of thaxtomin A is formed from L-phenylalanine and 4-NO2-L-Trp by two non-ribosomal peptide synthetases (NRPSs), TxtA and TxtB, each of which carries an $N$ methyltransferase domain. ${ }^{21}$ Another pathway-specific CYP, TxtC, then hydroxylates the cyclic dipeptide to complete the biosynthesis. The stereochemistry of the diketopiperazine core and the presence of the nitro group are critical for thaxtomin A's virulence activity. ${ }^{17}$ A bacterial nitric oxide synthase (bNOS), TxtD, oxidizes L-arginine (L-Arg) to form L-citrulline (L-Cit) and the necessary NO for the direction nitration reaction by TxtE: ${ }^{22-24}$ 


$$
\left.2 \mathrm{~L}-\mathrm{Arg}+3 \mathrm{NADPH}+4 \mathrm{O}_{2}+\mathrm{H}+\rightarrow 2 \mathrm{~L}-\mathrm{Cit}+2 \mathrm{NO}+3 \mathrm{NADP}^{+}+4 \mathrm{H}_{2} \mathrm{O} \text {. (eq. } 1\right)
$$

A similar NO-dependent nitration pathway was found in the biosynthesis of rufomycin by Streptomyces atratus. ${ }^{25}$ In this pathway, the enzyme RufO is a CYP homolog that nitrates Ltyrosine (L-Tyr) to the rufomycin precursor 3-nitro-L-tyrosine.

It has been expected that the TxtE nitration pathway shares early intermediates observed on the canonical CYP hydroxylation pathway, and therefore, we will briefly discuss the canonical pathway (Fig. 1), which has been reviewed elsewhere. ${ }^{26-29}$ The resting state CYP is in the low-spin ferric $\left(\mathrm{Fe}^{\mathrm{III}}\right)$ oxidation state with a coordinated water bound to the iron trans to the conserved cysteine ligand. Substrate binding promotes dissociation of the coordinated water, a shift in the spin equilibrium towards a high-spin $\mathrm{Fe}^{\mathrm{III}}$ center, and an increase in the heme reduction potential. Reduction of the active site forms an $\mathrm{Fe}^{\mathrm{II}} \mathrm{CYP}$, which allows for $\mathrm{O}_{2}$ to bind to form a ferricsuperoxide, denoted here in Enemark-Feltham notation ${ }^{30}$ as $\left\{\mathrm{FeO}_{2}\right\}^{8}$. Reduction and subsequent protonation of the $\left\{\mathrm{FeO}_{2}\right\}^{8}$ intermediate results in formation of a ferric-hydroperoxo species (Fe $\mathrm{FII}^{\mathrm{II}}$ $\mathrm{OOH}$ ), which is sometimes referred to as compound 0. Protonation of the Fe $\mathrm{Fe}^{\mathrm{III}}-\mathrm{OOH}$ species promotes heterolytic cleavage of the $\mathrm{O}-\mathrm{O}$ bond to form water and the active oxidant, compound I. Compound I enables $\mathrm{H}$-atom abstraction of the substrate to form a substrate radical and compound II. Radical rebound results in formation of hydroxylated product. The catalytic cycle is closed upon dissociation of the hydroxylated product and water coordination to regenerate the lowspin $\mathrm{Fe}^{\mathrm{III}}-\mathrm{OH}_{2}$ site. While compound I is the critical reactive intermediate needed to enable several CYP activities, some CYPs have evolved to leverage other intermediates on this pathway to catalyze less common reactions. 


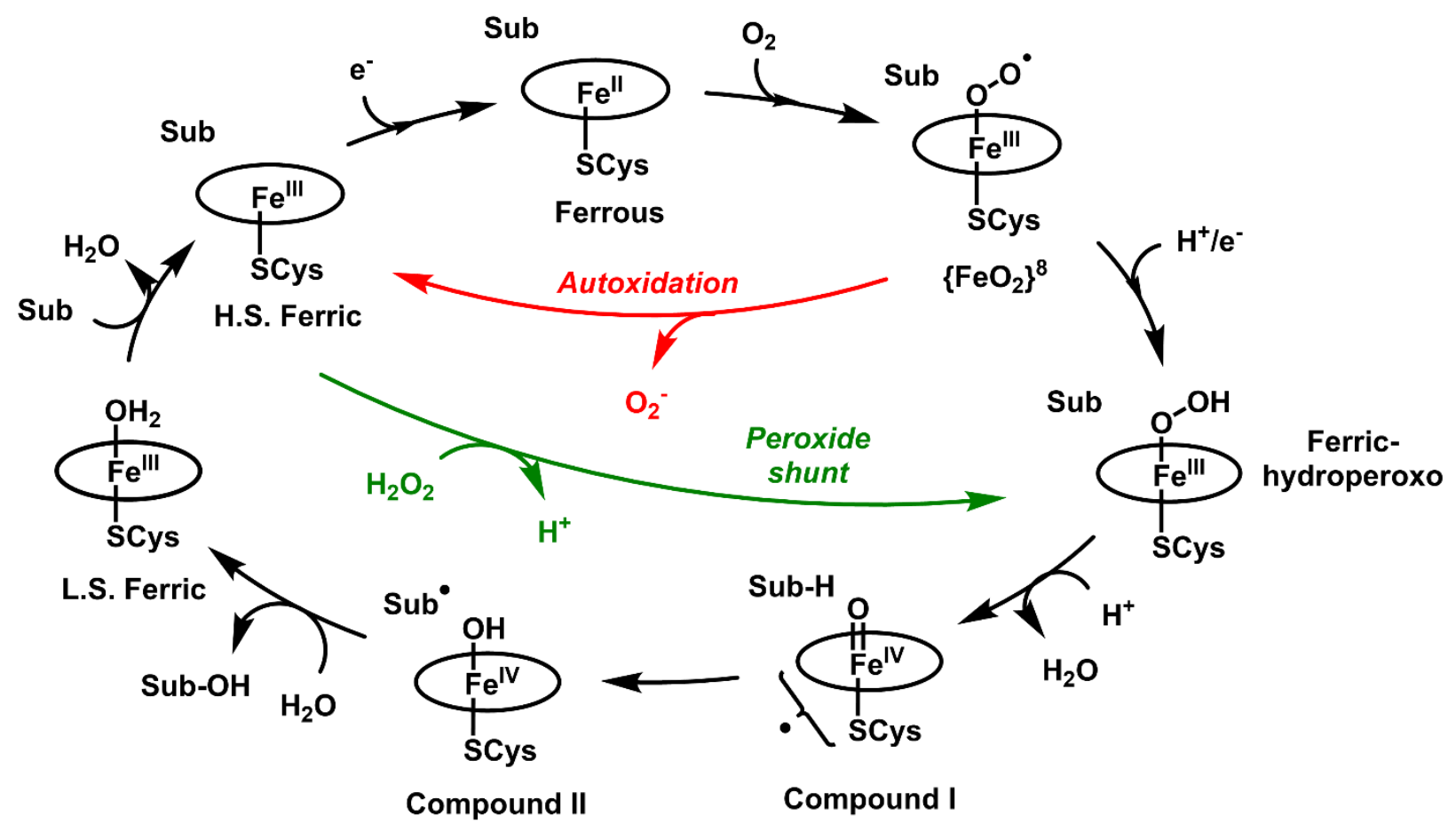

Figure 1. Canonical reaction mechanism for substrate (Sub) hydroxylation by CYPs.

Some CYP homologs or variants also exhibit poor electron coupling due to disruptions in water channels that aid in protonation or stabilization of pathway intermediates. One result of, so-called, electron uncoupling is that electrons needed for productive turnover are instead diverted to reduction of $\mathrm{O}_{2}$ to generate reactive oxygen species. Poor electron coupling to product formation has been reported for both TxtE and RufO. ${ }^{5,11}$ Therefore for the purpose of this study, we introduce two typical CYP uncoupling pathways. First, is the autoxidation pathway, in which superoxide $\left(\mathrm{O}_{2}{ }^{-}\right)$is dissociated from the $\left\{\mathrm{FeO}_{2}\right\}^{8}$ intermediate to regenerate the high-spin $\mathrm{Fe}^{\mathrm{III}} \mathrm{CYP}$ (Fig. 1, red pathway). A second pathway is the peroxide shunt, from which diffusible hydrogen peroxide $\left(\mathrm{H}_{2} \mathrm{O}_{2}\right)$ and the $\mathrm{Fe}^{\mathrm{III}}$ CYP are generated from the $\mathrm{Fe}^{\mathrm{III}}-\mathrm{OOH}$ intermediate (Fig. 1, green pathway). Of note, reversing the peroxide shunt by adding $\mathrm{H}_{2} \mathrm{O}_{2}$ to the $\mathrm{Fe}^{\mathrm{III}} \mathrm{CYP}$ generates the $\mathrm{Fe}^{\mathrm{III}}-\mathrm{OOH}$ intermediate, allowing for substrate hydroxylation without the need for NADPH, electron transfer (ET) partners, or $\mathrm{O}_{2}$, as observed in some $\mathrm{P} 450$ peroxygenases. ${ }^{31}$ 
Nitrations of L-Tyr and L-Trp are well studied in the context of nitrosative stress—cell damage resulting from cellular exposure to NO. ${ }^{32-33}$ These lesions can affect protein folding, aggregation, and function. ${ }^{33-36}$ Protein nitration is most often attributed to the formation of peroxynitrite $\left(\mathrm{ONOO}^{-}\right)$, resulting from the reaction of $\mathrm{NO}$ with $\mathrm{O}_{2}{ }^{-} \cdot{ }^{37}$ Protonation of $\mathrm{ONOO}^{-}$or its reaction with carbon dioxide initiates its decomposition to radical species—hydroxyl radical $(\cdot \mathrm{OH})$ or carbonate radical $\left(\cdot \mathrm{CO}_{3}{ }^{-}\right)$and nitrogen dioxide $\left(\cdot \mathrm{NO}_{2}\right)$-that directly enact nitration. ${ }^{33}, 38$ Alternative nitration pathways mediated by metals or metalloproteins also play prominent roles by promoting formation of $\cdot \mathrm{NO}_{2}$ and highly oxidizing metal-oxo species. ${ }^{39-44}$ One intermediate that has been proposed is a ferric-peroxynitrite ( $\mathrm{Fe} \mathrm{e}^{\mathrm{III}}-\mathrm{OONO}$ ) species. ${ }^{39}$ In fact, there is evidence that $\mathrm{Fe}^{\mathrm{III}}$ myoglobin reacts with $\mathrm{ONOO}^{-}$to form $\cdot \mathrm{NO}_{2}$ and the metal-oxo species, compound II, that together, are proposed to enable nitration. ${ }^{33,44-46}$ Such an intermediate has also been proposed for the NO dioxygenase pathway of flavohemoglobins. ${ }^{45,47}$ However, to date, metal-peroxynitrites have proved difficultto trap and characterize in all but synthetic model complexes. ${ }^{46}$, 48-50

Several proposed TxtE mechanisms invoke the need for both metal-oxo species and a $\mathrm{Fe}^{\mathrm{III}}$ OONO intermediate as pathway intermediates. ${ }^{4,51-52}$ These mechanistic proposals were largely based on the results of stable isotope labeling studies. Turnover of TxtE in an ${ }^{18} \mathrm{O}_{2}$ atmosphere and with an NO donor (e.g. DEA-NONOate) resulted in incorporation of one ${ }^{18} \mathrm{O}$ into the nitro group of 4-NO2-L-Trp. The second nitro oxygen likely originates from NO.22 The results are consistent with early formation of an $\mathrm{Fe}^{\mathrm{III}}-\mathrm{OONO}$ intermediate in the pathway.

A recent mechanistic study of TxtE by Louka, et al. provided the first direct characterization of TxtE pathway intermediates. ${ }^{1}$ While the Fe ${ }^{\text {III }}$-OONO intermediate was not directly observed, the results support the feasibility of its intermediacy. It was shown that the $\mathrm{Fe}^{\mathrm{II}} \mathrm{TxtE}$ reacted with $\mathrm{O}_{2}$ to form an $\left\{\mathrm{FeO}_{2}\right\}^{8}$ intermediate (Fig. 1). While NO was also shown to bind to the $\mathrm{Fe}^{\mathrm{II}}$ TxtE to 
form a ferrous-nitrosyl $\left(\{\mathrm{FeNO}\}^{7}\right)$, the authors provided convincing evidence that $\mathrm{O}_{2}$ binding to $\mathrm{Fe}^{\mathrm{II}}$ precedes its reaction with NO: 1$)$ the association rate constant for $\mathrm{O}_{2}\left(k_{\mathrm{a}(\mathrm{O} 2)}=4.43 \times 10^{6} \mathrm{M}^{-1} \mathrm{~s}^{-}\right.$ $\left.{ }^{1}\right)$ is faster than that for $\mathrm{NO}\left(\mathrm{k}_{\mathrm{a}(\mathrm{NO})}=1.82 \times 10^{6} \mathrm{M}^{-1} \mathrm{~s}^{-1}\right)$, 2) reacting the $\mathrm{TxtE}\left\{\mathrm{FeO}_{2}\right\}^{8}$ with $\mathrm{NO}$ results in its immediate disappearance within the stopped-flow deadtime, whereas the reaction of TxtE $\{\mathrm{FeNO}\}^{7}$ with $\mathrm{O}_{2}$ is significantly slower and decayed slowly over $100 \mathrm{~s}$, 3) reacting TxtE $\left\{\mathrm{FeO}_{2}\right\}^{8}$ with $\mathrm{NO}$ also results in a higher yield of $4-\mathrm{NO}_{2}$-L-Trp than the alternative reaction of $\{\mathrm{FeNO}\}^{7}$ with $\mathrm{O}_{2}$, and 4) transition state calculations showed that reaction of $\left\{\mathrm{FeO}_{2}\right\}^{8}$ with $\mathrm{NO}$ had a lower barrier than the alternative pathway. The accumulated evidence suggested a pathway in which the $\left\{\mathrm{FeO}_{2}\right\}^{8}$ intermediate reacts with $\mathrm{NO}$ to form a putative $\mathrm{Fe}{ }^{\mathrm{III}}-\mathrm{OONO}$ intermediate. Calculations were presented of feasible L-Trp nitration pathways resulting from the $\mathrm{Fe}^{\mathrm{III}}-\mathrm{OONO}$ intermediate that also accounted for the regiospecificity of the reaction.

This recent report establishes that a key difference between TxtE and canonical CYPs is the reactivity of the $\left\{\mathrm{FeO}_{2}\right\}^{8}$ intermediate; in TxtE $\left\{\mathrm{FeO}_{2}\right\}^{8}$ reacts with NO, whereas in canonical CYPs $\left\{\mathrm{FeO}_{2}\right\}^{8}$ is reduced (Fig. 1). Given the common intermediate for both cycles, it is not clear how TxtE avoids producing both 4-NO2-L-Trp and the hydroxylated product L-Trp-OH. Competition for the $\left\{\mathrm{FeO}_{2}\right\}^{8}$ intermediate in such a way would drastically lower the electron coupling efficiency of L-Trp nitration by TxtE. Indeed, TxtE has been reported to exhibit poor electron coupling with product accounting for only $2 \%$ of the consumed NADPH. ${ }^{10-11}$ However, prior work specifically noted that no hydroxylated product was observed. ${ }^{4}$

Herein, we present evidence that the $\mathrm{TxtE}\left\{\mathrm{FeO}_{2}\right\}^{8}$ intermediate resists reduction. For the first time, we report the observation of L-Trp-OH during turnover conditions of the engineered selfsufficient TxtE variant, TB14. The formation of the hydroxylated product was attributed to the peroxide shunt but not reduction of heme-bound $\mathrm{O}_{2}$ as observed for canonical CYPs. The presence 
of excess electrons and ET partners has no effect on the rate of conversion of $\left\{\mathrm{FeO}_{2}\right\}^{8}$ to L-Trpbound $\mathrm{Fe}^{\mathrm{III}} \mathrm{TxtE}$ as suggested by UV-vis absorption time courses. Finally, we show that nitration is highly efficient under single-turnover conditions. The combined results suggest that a key feature of TxtE is to resist reduction of the $\left\{\mathrm{FeO}_{2}\right\}^{8}$ intermediate, allowing for efficient nitration while avoiding competing hydroxylation activity, highlighting the high evolutionary versatility of CYPs.

\section{Methods}

Materials and general protocols

The plasmid for putidaredoxin expression (pPdX) was obtained from AddGene (Plasmid \#85084) and the recombinant protein purified and expressed as previously described. ${ }^{53}$ DEA- and PROLI-NONOates were purchased from Cayman Chemicals. DEA and PROLI-NONOate stocks were dissolved in $10 \mathrm{mM} \mathrm{NaOH}$ and quantified by measuring the absorbance at $250\left(\varepsilon_{250}=6500\right.$ $\left.\mathrm{M}^{-1} \mathrm{~cm}^{-1}\right)$ or $252 \mathrm{~nm}\left(\varepsilon=8400 \mathrm{M}^{-1} \mathrm{~cm}^{-1}\right)$, respectively. General reagents and media components were purchased from Fisher Scientific or VWR. Isopropyl $\beta$-D-1-thiogalactopyranoside (IPTG) and 5-aminolevulinic acid (5-ALA) were purchased from GoldBio. Water used for all solutions was of $18.2 \mathrm{M} \Omega \cdot \mathrm{cm}$ resistivity from a Barnstead Nanopure (Thermo Fisher Scientific). Solvents for LC-MS experiments were of at least HPLC grade and contained $0.3 \% \mathrm{v} / \mathrm{v}$ formic acid.

\section{TxtE expression and purification}

The TxtE plasmid was transformed into E. coli Lemo21 (DE3) or BL21 (DE3) competent cells by heat shock. The transformation solution was used to inoculate a 5-mL Terrific Broth (TB) starter culture containing $30 \mu \mathrm{g} / \mathrm{mL}$ chloramphenicol and $50 \mu \mathrm{g} / \mathrm{mL}$ kanamycin. This starter culture was 
incubated overnight at $37^{\circ} \mathrm{C}$ and $185 \mathrm{rpm}$. One milliliter of starter culture was used to inoculate 1-L of TB also containing chloramphenicol and kanamycin (same concentrations above). These 1L cultures were grown at $185 \mathrm{rpm}$ and $37^{\circ} \mathrm{C}$ until an OD600 of $\sim 0.8$ was obtained. At this point, all cultures were induced with $1 \mathrm{mM}$ IPTG and supplemented with $100 \mathrm{mg}$ each of $\left(\mathrm{NH}_{4}\right)_{5}\left[\mathrm{Fe}\left(\mathrm{C}_{6} \mathrm{H}_{4} \mathrm{O}_{7}\right)_{2}\right]$ (ferric ammonium citrate, FAC) and 5-ALA. The induced cultures were incubated at $21{ }^{\circ} \mathrm{C}$ and $185 \mathrm{rpm}$ for approximately 40 hours before being harvested via centrifugation at $4000 \mathrm{x}$ g. The cell pellets were resuspended in $25 \mathrm{mM}$ Tris, $250 \mathrm{mM} \mathrm{NaCl}, \mathrm{pH}$ 8.0 with $0.2 \mathrm{mM}$ phenylmethanesulfonyl fluoride (PMSF) and lysed either by sonication or French press. Lysates were centrifuged at $45000 \mathrm{xg}$ for 1.5 hours and the supernatant collected for further purification.

Purification of TxtE (MW $\approx 46 \mathrm{kDa}$ ) was accomplished by loading the lysate onto TALON ${ }^{\circledR}$ Superflow cobalt affinity resin (GE Healthcare Life Sciences) equilibrated with 25 mM Tris, 250 mM NaCl, 25 mM imidazole, pH 8.0 (Buffer A) using an NGC FPLC system (Bio-Rad). Once lysate was loaded, the column was washed with Buffer A until the $\mathrm{A}_{280}$ reached a minimum. TxtE was eluted from the column using a linear gradient of 100\% Buffer A to $100 \% 25 \mathrm{mM}$ Tris, 250 mM NaCl, 500 mM imidazole, pH 8.0 (Buffer B) over 10 minutes. All steps utilized a flow rate of $5 \mathrm{~mL} / \mathrm{min}$ except for lysate loading which was performed at $2.5 \mathrm{~mL} / \mathrm{min}$. Fractions with significant $\mathrm{A}_{280}$ were collected, pooled, and de-salted (removing imidazole) using PD-10 columns (GE Healthcare Life Sciences) with the gravity protocol, and exchanged into $100 \mathrm{mM}$ Tris, $\mathrm{pH}$ 8.0. Following de-salting, the protein was concentrated down in $30 \mathrm{kDa}$ cutoff Amicon filters by centrifuging at $4000 \mathrm{x}$ g. The concentrated protein was checked for purity by SDS-PAGE and quantified using Pierce ${ }^{\mathrm{TM}}$ Rapid Gold BCA assay (Thermo Fisher Scientific). Purified protein samples were stored at $-60^{\circ} \mathrm{C}$. 
The expression and purification of TB14 enzyme $(\mathrm{MW} \approx 112 \mathrm{kDa})$ was similar to the protocol for TxtE except plasmids were transformed into E. coli BL21 (DE3) cells.

\section{Preparation of LC-MS samples}

For catalase experiments, samples were prepared aerobically containing $5 \mu \mathrm{M}$ TB14, $1 \mathrm{mM}$ NADPH, $500 \mu \mathrm{M}$ L-Trp and $1 \mu \mathrm{M}$ catalase. The control had no catalase. Samples allowed to incubate for 2 hours before being filtered with $0.45 \mu \mathrm{M}$ syringe filters into autosampler vials for LC-MS analysis.

For single turnover experiments, a 1500- $\mu \mathrm{l}$ anaerobic sample containing $100 \mu \mathrm{M}$ TxtE and 500 $\mu \mathrm{M}$ L-Trp was titrated with dithionite until fully reduced,monitored by UV-vis absorbance (Soret shift to $\sim 412 \mathrm{~nm}$ indicates reduction of the heme iron). The titration was performed inside a glovebox with a nitrogen atmosphere $\left(<5 \mathrm{ppm}_{2}\right)$. Following reduction, the protein sample was divided into three $500 \mu \mathrm{L}$ aliquots contained in microcentrifuge tubes. A small volume (roughly $10 \mu \mathrm{L}$ ) of the PROLI-NONOate stock to generate $1.7 \mathrm{mM}$ NO after mixing was pipetted onto the cap of the microcentrifuge tube, well separated from the protein solution. The samples were removed from the box and exposed to air and capped (introducing the NONOate to the mixture). Samples were incubated at room temperature $\left(\sim 21^{\circ} \mathrm{C}\right)$ for 30 minutes. The samples were centrifuged through $30 \mathrm{kDa}$ cutoff Microcon centrifugal filters (Millipore) to remove the TxtE. The flowthrough was filtered using $0.45 \mu \mathrm{M}$ syringe filters and analyzed by HPLC. Steady-state TB14 samples were prepared aerobically with $0.5 \mu \mathrm{M}$ TB14, $500 \mu \mathrm{M}$ L-Trp, 2 mM NADPH, and 1.33 mM DEA NONOate (delivered 2 mM NO) in 100 mM Tris, pH 8.0 and allowed to react for 30 minutes at room temperature prior to filtration as above and analyzed by HPLC. 
Single turnover samples for TB14 were prepared in a similar fashion to those for TxtE except NADPH was used as the electron source. Samples were prepared in nitrogen atmosphere and contained $20 \mu \mathrm{M}$ TB14, $500 \mu \mathrm{M}$ L-Trp, and between 10 and $40 \mu \mathrm{M}$ NADPH (0.5, 1.0, 2.0 eq NADPH per protein monomer) and incubated in the glovebox for 30 minutes to allow for reduction of the TB14. Addition of $1 \mathrm{mM}$ PROLI-NONOate and air was performed as described for TxtE samples. After initiating the reaction, the samples were incubated for 30 minutes at $21^{\circ} \mathrm{C}$. Samples were prepared for HPLC analysis as described above for TxtE samples.

\section{General LC-MS protocols}

All LC-MS samples were passed through $0.45 \mu \mathrm{M}$ syringe filters into autosampler vials prior to LC-MS analysis. LC-MS analysis was performed using an Agilent 1260 LC stack connected to an Agilent 6230 TOF mass spectrometer with electrospray ionization (ESI). Unless otherwise noted, analyses used a gradient of water (Solvent A) and acetonitrile (Solvent B) for the following times; percentages are with respect to Solvent B: 0-1 min (1\%), 1-8 min (1-20\%), 8-10 min (20-99\%), 10-12 $\mathrm{min}(99 \%), 12-13(1 \%)$. The flow rate was set at $1.0 \mathrm{~mL} / \mathrm{min}$. Unless otherwise noted, the mass spectrometer was run in negative ion mode with a probe voltage of $4500 \mathrm{~V}$ and fragmentation voltage of $175 \mathrm{~V}$. To monitor L-Trp, L-Trp-OH, and L-NO $2-T r p$, extracted ion chromatograms were obtained with $m / z=203$ (203.0180), $m / z=219$ (219.0793), and $m / z=248$ (247.9937), respectively.

The quantitation of 4-NO2-L-Trp was performed with a Shimadzu Prominence UHPLC system (Kyoto, Japan) fitted with an Agilent Poroshell 120 EC-C18 column (2.7 $\mu \mathrm{m}, 4.6$ by $50 \mathrm{~mm}$ ) coupled with a photodiode array (PDA) detector. The HPLC program included column equilibration first with $10 \%$ solvent B (acetonitrile with $0.1 \%$ formic acid) for 2 min and then with a linear gradient of 10 to $50 \%$ solvent B over 8 min, followed by another linear gradient of 50 to 
99\% solvent B over 5 min. The column was further cleaned with 99\% solvent B for 3 min and then reequilibrated with $10 \%$ solvent B for 1 min. Solvent A was water with $0.1 \%$ FA. The flow rate was set as $0.5 \mathrm{~mL} / \mathrm{min}$, and $4-\mathrm{NO}_{2}-\mathrm{L}-\mathrm{Trp}$ was detected at $380 \mathrm{~nm}$.

\section{General stopped-flow protocols}

Stopped-flow measurements were performed on an SX20 stopped-flow spectrophotometer (Applied Photophysics) equipped with a xenon arc lamp, monochromator, and a photodiode array detector. For anaerobic experiments, enzyme samples and reagents were prepared within a glovebox containing nitrogen atmosphere. The stopped-flow lines were made anaerobic by flushing the drive syringes and mixing circuit with sodium dithionite to remove all $\mathrm{O}_{2}$. The dithionite was then rinsed with deoxygenated working buffer (100 mM Tris, pH 8.0) immediately before loading experimental samples. All single-mix experiments were mixed at a 1:1 $(v / v)$ ratio. For sequential-mix experiments, A and B lines were mixed at a 1:1 $(v / v)$ ratio in the pre-mix line. The pre-mix line was then mixed at a 1:1 ( $v / v)$ ratio with the $C$ line. Conditions after mixing are listed in the figure captions. Analytical fits of sums of exponents to single-wavelength data were performed using non-linear regression in Origin 2018b (Originlab corporation). Global fitting of spectral time courses was performed using KinTek explorer (KinTek Corporation).

\section{TxtE and TB14 vs $\mathrm{O}_{2}$ stopped-flow experiments}

Working buffer for stopped-flow experiments was composed of $100 \mathrm{mM}$ Tris, pH 8.0. To obtain measurements of the apparent autoxidation rate constants, enzyme was reduced inside a glovebox with stoichiometric amounts of sodium dithionite. Full reduction of TxtE and TB14 was verified by monitoring the reduction by UV-vis absorption spectrophotometry in the glovebox by 
monitoring the appearance of the Soret band of $410 \mathrm{~nm}$ indicative of the reduced heme center. The reduced enzyme was anaerobically transferred and loaded into the drive syringe. Reduced enzyme was mixed with deoxygenated buffer to obtain the spectrum of the reduced protein. Autoxidation time courses were recorded after mixing reduced TxtE with air-saturated $\left(\sim 260 \mu \mathrm{M} \mathrm{O}_{2}\right)$ working buffer.

TxtE with $P d X_{\text {red }}$ vs $\mathrm{O}_{2}$ stopped-flow experiments

Working buffer for stopped-flow experiments was composed of $100 \mathrm{mM}$ Tris, $\mathrm{pH}$ 8.0. A solution containing $30 \mu \mathrm{M}$ TxtE and $500 \mu \mathrm{M}$ L-Trp in deoxygenated working buffer was reduced anaerobically as described above. Separately, an anaerobic solution of $100 \mu \mathrm{M} \mathrm{PdX}$ in deoxygenated working buffer was reduced by titration with dithionite solution. The reduction was monitored by the disappearance of peaks in the 400-450 region and appearance of a new peak at $550 \mathrm{~nm} .{ }^{54}$ The $P d X_{\text {red }}$ solution was added to the $\mathrm{Fe}^{\mathrm{II}} \mathrm{TxtE}$ solution to obtain a final concentration of $30 \mu \mathrm{M} P d X_{\text {red. }}$ This solution was loaded anaerobically into the mixing circuit and mixed against either anaerobic or air-saturated working buffer.

$T x t E\left\{\mathrm{FeO}_{2}\right\}^{8}$ vs. NO stopped-flow experiments

Sequential-mix stopped-flow was used to monitor the reaction of $\operatorname{TxtE}\left\{\mathrm{FeO}_{2}\right\}^{8}$ vs. NO. Working buffer for these experiments was $100 \mathrm{mM}$ Tris, $\mathrm{pH}$ 8.0. A sample of $40 \mu \mathrm{M}$ TxtE with $1 \mathrm{mM} \mathrm{L}-$ Trp was reduced with stoichiometric dithionite as described for the autoxidation experiments. In the first mixing step, this solution was mixed with air-saturated $\left(\sim 260 \mu \mathrm{M} \mathrm{O}_{2}\right)$ working buffer and aged in the pre-mix circuit for $1 \mathrm{~s}$. After aging, this mixture was mixed with either $1.33 \mathrm{mM}$ DEA $1.2 \mathrm{mM}$ buffered NO. 


\section{Results}

TxtE hydroxylates L-Trp via the peroxide shunt

Prior work reported that TxtE with spinach ferredoxin and ferredoxin oxidoreductase as electron transfer (ET) partners could not hydroxylate L-Trp under turnover conditions in either the absence or presence of NO. ${ }^{4}$ We repeated turnover experiments using TB14, an engineered self-sufficient TxtE variant we developed previously. ${ }^{10-11}$ In this variant, TxtE is linked with the reductase domain of CYP102A1 at the C-terminus with a 14-amino acid linker. This variant catalyzes L-Trp nitration in the presence of NADPH, L-Trp, $\mathrm{O}_{2}$ and NO without additional ET partners. Under these conditions, we observed no formation of L-Trp-OH (Fig. 2, green trace). In contrast, when NO was excluded (referred to as the $\mathrm{O}_{2}$ turnover conditions), the LC-MS extracted ion chromatogram $(m / z=219.08)$ of the enzyme reaction revealed a peak at $3.06 \mathrm{~min}$ (Fig. 2, purple trace). This $\mathrm{m} / \mathrm{z}$ value is consistent with the $[\mathrm{M}-\mathrm{H}]^{-}$of L-Trp-OH.

The poor electron coupling previously reported for $\mathrm{TB} 14$ and $\mathrm{TxtE}^{10-11}$ suggests that the enzyme frequently undergoes unproductive turnovers to generate $\mathrm{H}_{2} \mathrm{O}_{2}$ directly or indirectly from uncoupling at the $\left\{\mathrm{FeO}_{2}\right\}^{8},\left\{\mathrm{FeO}_{2}\right\}^{9}$, or Fe ${ }^{\mathrm{III}}-\mathrm{OOH}$ intermediates (Fig. 1). Alternatively, $\mathrm{H}_{2} \mathrm{O}_{2}$ may be generated by $\mathrm{O}_{2}$ reduction by the TB14 reductase domain. ${ }^{55}$ To test the potential involvement of diffusible $\mathrm{H}_{2} \mathrm{O}_{2}$ in the L-Trp hydroxylation, the TB14 $\mathrm{O}_{2}$-turnover experiments were repeated in the presence of $5 \mu \mathrm{M}$ catalase, a $\mathrm{H}_{2} \mathrm{O}_{2}$ scavenger. We observed no $\mathrm{m} / \mathrm{z} 219.08$ signal from these samples in LC-MS analysis (Fig. 2, gold trace), clearly indicating that L-Trp-OH formation requires the presence of diffusible $\mathrm{H}_{2} \mathrm{O}_{2}$.

The need of $\mathrm{H}_{2} \mathrm{O}_{2}$ for L-Trp hydroxylation was directly tested by exposing TB14 to peroxide shunt conditions. We incubated TB14 (5 $\mu \mathrm{M}), \mathrm{H}_{2} \mathrm{O}_{2}(5 \mathrm{mM})$, and L-Trp (500 $\left.\mu \mathrm{M}\right)$ together for 2 hours. The LC-MS analysis of these samples identified one small $\mathrm{m} / \mathrm{z} 219.08$ peak at $2.30 \mathrm{~min}$ and 
one large peak at 3.07 min. (Fig. 2, cyan trace and Fig. S1). The latter peak elutes at the same time as that observed under TB14 $\mathrm{O}_{2}$-turnover conditions. No m/z 219.08 signal was observed in the control without TB14, indicating that L-Trp-OH formation requires enzyme (Fig. 2, black trace). The appearance of two peaks is interpreted as formation of two regioisomers of L-Trp-OH, suggesting that hydroxylation by TxtE is not strictly regiospecific. Nonetheless, these results strongly suggest TB14 not only supports l-Trp nitration but that in addition to l-Trp nitration but can also hydroxylate L-Trp by the peroxide shunt. We observed similar results with TxtE in place of TB14 (Fig. 2, blue trace), indicating that the reductase domain of TB14 is not required for LTrp hydroxylation by the peroxide shunt. Taken together, these results suggest that TxtE uncoupling (Fig. 1) generates diffusible $\mathrm{H}_{2} \mathrm{O}_{2}$. This $\mathrm{H}_{2} \mathrm{O}_{2}$ then enables the L-Trp hydroxylation by TxtE via the peroxide shunt but not by reduction of heme-bound $\mathrm{O}_{2}$ in canonical CYPs.

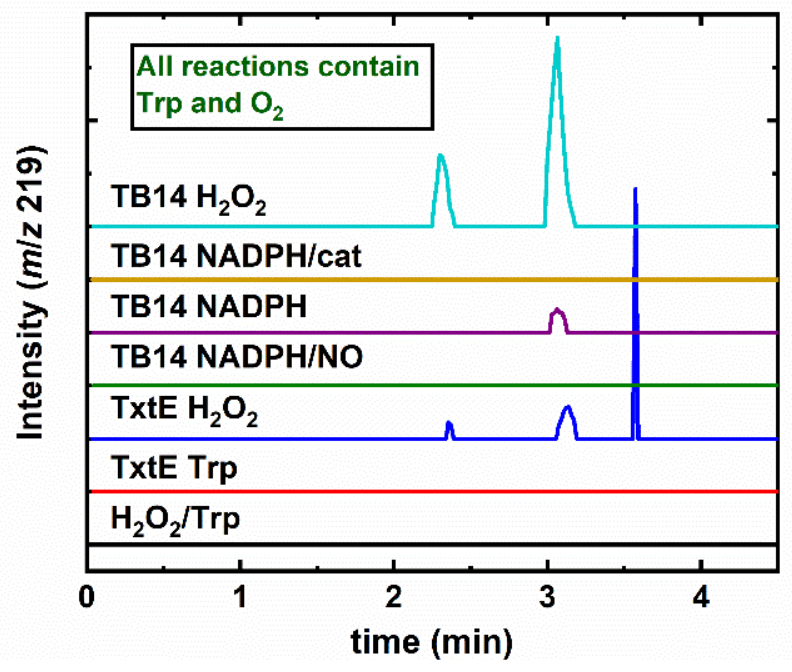

Figure 2. Representative LC-MS extracted ion chromatograms $(m / z=219.08)$ of TxtE and TB14 reactions. All reaction mixtures contained $500 \mu \mathrm{M}$ L-Trp in $100 \mathrm{mM}$ Tris buffer, $\mathrm{pH}$ 8.0. The samples contained the additional components: $3 \mathrm{mM} \mathrm{H}_{2} \mathrm{O}_{2}$ (black); $40 \mu \mathrm{M}$ TxtE (red); $40 \mu \mathrm{M}$ TxtE and $3 \mathrm{mM} \mathrm{H} \mathrm{O}_{2}$ (blue); $40 \mu \mathrm{M}$ TB14, $2 \mathrm{mM}$ NADPH, and $1.33 \mathrm{mM}$ DEA-NONOate (green); 5 $\mu \mathrm{M}$ TB14 and $500 \mu \mathrm{M}$ NADPH (purple); $5 \mu \mathrm{M}$ TB14, $500 \mu \mathrm{M}$ NADPH, and $5 \mu \mathrm{M}$ catalase (cat) 
(gold); and $5 \mu \mathrm{M}$ TB14 and $5 \mathrm{mM} \mathrm{H}_{2} \mathrm{O}_{2}$ (cyan). All samples were incubated at room temperature for 120 (TB14 samples) or 30 minutes (all others) prior to analysis.

\section{$\mathrm{TxtE}\left\{\mathrm{FeO}_{2}\right\}^{8}$ autoxidation}

The reductase domain of TB14 originates from CYP102A, a self-sufficient CYP, which is the most efficient known CYP. ${ }^{56}$ Therefore, in the native system, the reductase domain is competent for $\left\{\mathrm{FeO}_{2}\right\}^{8}$ reduction and subsequent substrate hydroxylation. In addition, there are ample precedents that fusing the reductase domain to non-native CYP partners enables self-sufficient ET and substrate hydroxylation. ${ }^{57-58}$ Based on this precedent, it might be expected that the TB14 reductase domain could also reduce the TxtE $\left\{\mathrm{FeO}_{2}\right\}^{8}$ when loaded with excess reducing equivalents. However, our LC-MS results above show no evidence that TxtE/TB14 can hydroxylate L-Trp under nitration turnover conditions. One possibility for this observation is that the TxtE $\left\{\mathrm{FeO}_{2}\right\}^{8}$ intermediate cannot be reduced. To test this hypothesis, we compared the time courses of the $\mathrm{Fe}^{\mathrm{II}}$ TxtE reaction with $\mathrm{O}_{2}$ in the absence vs. presence of common CYP ET partners.

To monitor the intermediates formed in the absence of excess reducing equivalents, we monitored the reaction of $\mathrm{Fe}^{\mathrm{II}} \mathrm{TxtE}$ with $\mathrm{O}_{2}$ by stopped-flow $\mathrm{UV}$-vis absorption spectrophotometry (Fig. 3A). To obtain the spectrum of Fe ${ }^{\mathrm{II}} \mathrm{TxtE}$, an anaerobic solution of 10 $\mu \mathrm{M} \mathrm{Fe}^{\mathrm{II}} \mathrm{TxtE}$ with $500 \mu \mathrm{M}$ L-Trp in $\mathrm{pH} 8.0$ buffer was mixed at a 1:1 $(v / v)$ ratio with deoxygenated $\mathrm{pH} 8.0$ buffer at $20^{\circ} \mathrm{C}$. The $\mathrm{Fe}^{\mathrm{II}} \mathrm{TxtE}$ spectrum displayed absorbance features with maxima at 412 and $553 \mathrm{~nm}$, consistent with previously reported spectra. ${ }^{1}$ Mixing the $\mathrm{Fe}^{\mathrm{II}} \mathrm{TxtE}$ solution at a $1: 1(\mathrm{v} / \mathrm{v})$ ratio with air-saturated $\mathrm{pH} 8.0$ buffer at $20^{\circ} \mathrm{C}$ resulted in complete disappearance of the $\mathrm{Fe}^{\mathrm{II}} \mathrm{TxtE}$ absorption features within the mixing deadtime of $2 \mathrm{~ms}$. The deadtime spectrum showed absorption features with maxima at 365, 425, and $561 \mathrm{~nm}$, consistent 
with previously reported spectra for the TxtE $\left\{\mathrm{FeO}_{2}\right\}^{8}$ intermediate. ${ }^{1}$ This intermediate spectrum decayed over several minutes to a new species with spectral features centered at 402,412 , and $542 \mathrm{~nm}$ consistent with the L-Trp bound Fe ${ }^{\mathrm{III}}$ TxtE..$^{1,4,8,11}$ Isosbestic points at 357, 421, 493, 547, and $602 \mathrm{~nm}$ are consistent with a one-step conversion of TxtE $\left\{\mathrm{FeO}_{2}\right\}^{8}$ to L-Trp bound $\mathrm{Fe}^{\mathrm{III}}$ TxtE, indicating autoxidation of TxtE. The $\mathrm{A}_{400-\mathrm{nm}}$ trace, monitoring formation of the Fe ${ }^{\mathrm{III}} \mathrm{TxtE}$, and $\mathrm{A}_{442-\mathrm{nm}}$ trace, monitoring decay of the TxtE $\left\{\mathrm{FeO}_{2}\right\}^{8}$ intermediate, were both well fit to single-exponential functions (Fig. 3A, inset) with $k_{\text {obs }}$ of approximately $0.008(0.001) \mathrm{s}^{-1}$, which is assigned as the TxtE autoxidation rate constant ( $k_{\text {autox; }}$ Table 1).

Omitting L-Trp increases the rate of TxtE autoxidation. We mixed an anaerobic solution of 10 $\mu \mathrm{M} \mathrm{Fe}{ }^{\mathrm{II}} \mathrm{TxtE}$ at a $1: 1(v / v)$ ratio with air-saturated $\mathrm{pH} 8.0$ buffer at $20^{\circ} \mathrm{C}$ (Fig. 3B). The deadtime spectrum had absorbance features centered at 421 and $561 \mathrm{~nm}$ and was nearly identical to the TxtE $\left\{\mathrm{FeO}_{2}\right\}^{8}$ intermediate spectrum in the presence of L-Trp. The decay time course of this intermediate was complete within $2 \mathrm{~s}$ with the final spectrum exhibiting absorbance features centered at 417 and $534 \mathrm{~nm}$. This spectrum is consistent with the low-spin $\mathrm{Fe}^{\mathrm{III}} \mathrm{TxtE}$, which is expected in the absence of L-Trp. Isosbestic points at 425, 502, 538, and $602 \mathrm{~nm}$ are consistent with a one-step conversion of TxtE $\left\{\mathrm{FeO}_{2}\right\}^{8}$ to low-spin Fe ${ }^{\mathrm{III}} \mathrm{TxtE}$ and autoxidation of TxtE. The 440-nm trace was well fit to a single exponent with a $k_{\text {obs }}$ of $3.7(0.3) \mathrm{s}^{-1}$ (Figure 3B, inset and Table 1). The stopped-flow UV-vis absorption analysis thus revealed that the autoxidation rate of the TxtE $\left\{\mathrm{FeO}_{2}\right\}^{8}$ is over 400 times faster in the absence of substrate L-Trp. This more rapid autoxidation in the absence of substrate is also observed for several other CYP homologs..$^{59-60}$ 

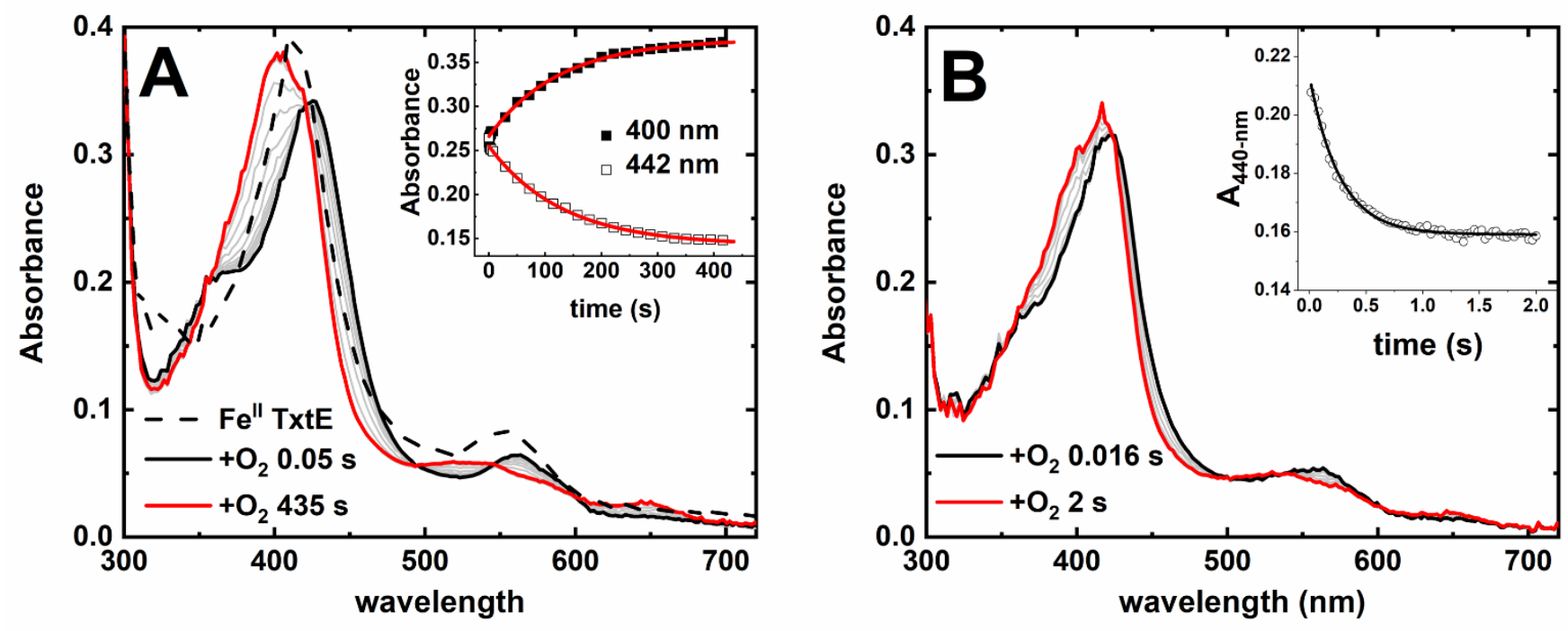

Figure 3. Stopped-flow spectral time courses of anaerobic $\mathrm{Fe}^{\mathrm{II}} \mathrm{TxtE}$ mixed with $\mathrm{O}_{2}$ in the presence (A) and absence (B) of L-Trp at $\mathrm{pH}$ 8.0. Dashed trace obtained by mixing Fe ${ }^{\mathrm{II}} \mathrm{TxtE}$ solution against deoxygenated buffer. Solid black and red traces are the first and last collected spectra in the time courses, respectively. Gray traces were collected at intermediate times. Inset: single-exponent fits to representative A) $\mathrm{A}_{400}$ and $\mathrm{A}_{442-\mathrm{nm}}$ or B) $\mathrm{A}_{440-\mathrm{nm}}$ traces. Final conditions: A) $5 \mu \mathrm{M} \mathrm{Fe}^{\mathrm{II}} \mathrm{TxtE}, 250$ $\mu \mathrm{M}$ L-Trp, $130 \mu \mathrm{M} \mathrm{O}_{2}$ and B) $5 \mu \mathrm{M}$ Fe ${ }^{\mathrm{II}} \mathrm{TxtE}, 130 \mu \mathrm{M} \mathrm{O}_{2}$. All solutions were in $100 \mathrm{mM}$ Tris, $\mathrm{pH}$ 8.0 and performed at $20^{\circ} \mathrm{C}$ in a $1 \mathrm{~cm}$ path length cuvette.

$\mathrm{TxtE}\left\{\mathrm{FeO}_{2}\right\}^{8}$ intermediate resists reduction by $\mathrm{PdX}$

Next, we tested the reduction of TxtE $\left\{\mathrm{FeO}_{2}\right\}^{8}$ in the presence of excess reducing equivalents and common CYP ET partners. First, we generated the $\left\{\mathrm{FeO}_{2}\right\}^{8}$ species in the presence of reduced putidaredoxin $\left(\mathrm{PdX} \mathrm{X}_{\mathrm{red}}\right)$. This one-electron ET protein is well studied critical for hydroxylation activity by CYP101A1. ${ }^{61-62}$ An anaerobic solution containing $30 \mu \mathrm{M} \mathrm{Fe}{ }^{\mathrm{II}} \mathrm{TxtE}, 30 \mu \mathrm{M}$ PdX $\mathrm{X}_{\text {red }}$ and $500 \mu \mathrm{M}$ L-Trp in $\mathrm{pH} 8.0$ buffer was mixed at a 1:1 $(\mathrm{v} / \mathrm{v})$ ratio with deoxygenated $\mathrm{pH} 8.0$ buffer at $20{ }^{\circ} \mathrm{C}$. Absorbance maxima were observed at 412 and $555 \mathrm{~nm}$ (Fig. 4A, dashed trace). These features are similar to the absorbance maxima observed for the $\mathrm{Fe}^{\mathrm{II}} \mathrm{TxtE}$ with minor differences 
likely attributed to the $P d X_{\text {red. }}$ We then mixed the enzyme solution at a 1:1 $(v / v)$ ratio with airsaturated buffer and observed immediate disappearance of the $\mathrm{Fe}^{\mathrm{II}} \mathrm{TxtE}$ spectrum and appearance of features at 427 and $559 \mathrm{~nm}$ (Fig. 4A). These absorbance features are similar to those assigned to the TxtE $\left\{\mathrm{FeO}_{2}\right\}^{8}$ intermediate. Thereafter, two phases were observed. The first phase was complete in $33 \mathrm{~s}$ and exhibited broad absorbance increases in the 350 to $550 \mathrm{~nm}$ region. The spectral features in this phase are attributed to oxidation of $\mathrm{PdX}$ red. ${ }^{54}$ The second phase occurred between 30 and $605 \mathrm{~s}$ (Fig. 4B). The final spectrum after $600 \mathrm{~s}$ had a broad absorbance maximum centered at $412 \mathrm{~nm}$. The time course of the $2^{\text {nd }}$ phase showed several isosbestic points at 421,502 , 542, and $606 \mathrm{~nm}$ and was consistent with autoxidation of TxtE. Additionally, the 561-nm trace from 70 to $605 \mathrm{~s}$ was well fit by a single exponent with a $k_{\text {obs }}$ of $0.0072(0.0015) \mathrm{s}^{-1}$, which is similar to the $k_{\text {obs }}$ for TxtE $\left\{\mathrm{FeO}_{2}\right\}^{8}$ autoxidation (Fig. 3).

The above analysis suggests the time course reports the following reaction scheme:

$$
\begin{array}{ll}
\mathrm{Fe}^{\mathrm{II}} \mathrm{TxtE}+\mathrm{O}_{2} \rightarrow\left\{\mathrm{FeO}_{2}\right\}^{8} \mathrm{TxtE} & \text { (eq. 2) } \\
\left\{\mathrm{FeO}_{2}\right\}^{8} \mathrm{TxtE} \rightarrow \mathrm{Fe}^{\mathrm{III}} \mathrm{TxtE}+\mathrm{O}_{2}{ }^{-} & \text {(eq. 3) } \\
\mathrm{Fe}^{\mathrm{III}} \mathrm{TxtE}+\mathrm{PdX}_{\text {red }} \rightarrow \mathrm{Fe}^{\mathrm{II}} \mathrm{TxtE}+\mathrm{PdX}_{\text {ox }} & \text { (eq. 4) }
\end{array}
$$

The initial formation of $\left\{\mathrm{FeO}_{2}\right\}^{8} \mathrm{TxtE}$ (eq. 2) upon mixing is rapid and nearly complete within the deadtime, and therefore, initial binding of $\mathrm{O}_{2}$ to $\mathrm{Fe}^{\mathrm{II}} \mathrm{TxtE}$ is not observed in the time course. Instead, the time course, reports oxidation of $\mathrm{PdX}_{\text {red }}$ (eq. 4) and autoxidation of TxtE (eq. 3). Single value decomposition (SVD) and global fitting of the time course to a two-step model (A $\rightarrow$ B $\rightarrow$ C) supports this interpretation (Fig. S2).

In the presence of 1 equivalent of $\mathrm{Pd} \mathrm{X}_{\text {red, }}$ these reactions were primed for either single turnover of $\left\{\mathrm{FeO}_{2}\right\}^{8}$ reduction or two turnovers of TxtE autoxidation. Previous work showed that cryoreduction of the CYP101A1 $\left\{\mathrm{FeO}_{2}\right\}^{8}$ intermediate to the $\left\{\mathrm{FeO}_{2}\right\}^{9}$ species results in a major 
shift of the Soret band from 417 to $440 \mathrm{~nm} .{ }^{63}$ There is no evidence for the accumulation of such spectral features either by inspection of the time course or in the component spectra resulting from global analysis. Prior studies with CYP101A1 show that rapid decay of the $\left\{\mathrm{FeO}_{2}\right\}^{8}$ to the Fe $\mathrm{III}$ species with a $k_{\text {obs }}$ of 85 to $140 \mathrm{~s}^{-1}$ at $3-4{ }^{\circ} \mathrm{C}$ or $390 \mathrm{~s}^{-1}$ at $25^{\circ} \mathrm{C} \cdot{ }^{64-67}$ In this work, we observed that the $k_{\text {autox }}$ for TxtE is statistically identical in the absence and presence of PdX $\mathrm{X}_{\text {red }}$ (Table 1). The first phase of the time course (Fig. 4A) is interpreted as reporting $\mathrm{PdX}_{\text {red, }}$ resulting from the first autoxidation turnover of TxtE. The second phase of the time course (Fig. 4B) is interpreted as reporting the second TxtE autoxidation turnover. The combined results suggest $\mathrm{TxtE}\left\{\mathrm{FeO}_{2}\right\}^{8}$ is resistant to reduction by $\mathrm{PdX}$ red. 

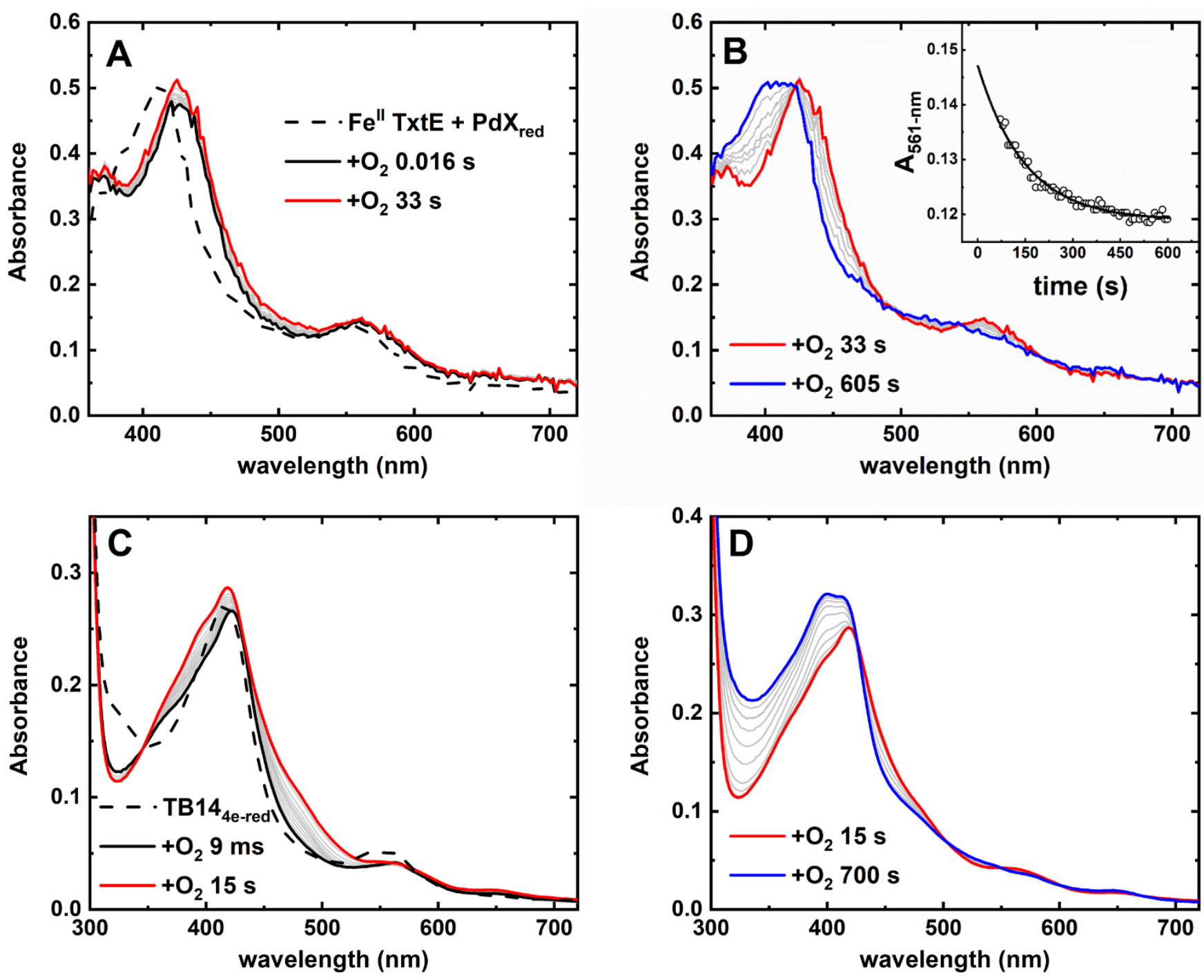

Figure 4. Stopped-flow spectral time courses of anaerobic Fe ${ }^{\mathrm{II}} \mathrm{TxtE}$ and $\mathrm{PdX}_{\text {red }}(\mathrm{A}$ and $\mathrm{B}$ ) or TB144e-red (C and D) mixed with $\mathrm{O}_{2}$ in the presence of excess L-Trp at pH 8.0 and $21{ }^{\circ} \mathrm{C}$. Dashed trace obtained by mixing the anaerobic solution against deoxygenated buffer. Solid black, red, or blue traces were collected at times indicated in the figure legends. Gray traces were collected at intermediate times. Inset: single-exponent fits to representative $\mathrm{A}_{561-\mathrm{nm}}$ traces. Conditions after mixing: A) $15 \mu \mathrm{M} \mathrm{Fe}^{\mathrm{II}} \mathrm{TxtE}, 15 \mu \mathrm{M}$ PdX $\mathrm{X}_{\text {red, }} 250 \mu \mathrm{M}$ L-Trp, $130 \mu \mathrm{M} \mathrm{O}_{2}$ and B) $20 \mu \mathrm{M}$ TB144e-red, $250 \mu \mathrm{M} \mathrm{L}$-Trp, and $130 \mu \mathrm{M} \mathrm{O}_{2}$. All solutions were in $100 \mathrm{mM}$ Tris, $\mathrm{pH} 8.0$ and measured at $20^{\circ} \mathrm{C}$ in a $1 \mathrm{~cm}$ path length cuvette. 
$\mathrm{TB} 14\left\{\mathrm{FeO}_{2}\right\}^{8}$ intermediate resists reduction by reductase domain

To test the ability of the TB14 reductase domain to reduce $\left\{\mathrm{FeO}_{2}\right\}^{8}$, 4-electron reduced TB14 (TB144e-red) was anaerobically prepared and reacted with $\mathrm{O}_{2}$ (Figs. 4C and 4D). An anaerobic solution of $20 \mu \mathrm{M}$ TB144e-red with $500 \mu \mathrm{M}$ L-Trp in anaerobic $\mathrm{pH} 8.0$ buffer was mixed at a 1:1 $(v / v)$ ratio with anaerobic $\mathrm{pH} 8.0$ buffer at $20^{\circ} \mathrm{C}$. The resulting time course showed the TB14 4 -red spectrum with absorbance features centered at 412 and $549 \mathrm{~nm}$ (Fig. 4C). These absorbance features are similar to those observed for the $\mathrm{Fe}^{\mathrm{II}} \mathrm{TxtE}$ with some differences due to the presence of the flavin cofactors in the reductase domain. Mixing the TB144e-red solution at a 1:1 $(v / v)$ ratio with air-saturated $\mathrm{pH} 8.0$ buffer resulted in the disappearance of the TB144e-red spectrum within the deadtime (Fig. 4C). The deadtime spectrum exhibits absorbance features centered at 361, 430, and $561 \mathrm{~nm}$. This spectrum was consistent with formation of the $\left\{\mathrm{FeO}_{2}\right\}^{8}$ intermediate in previously discussed time courses (Figs. 3 and $\mathbf{4}$ ).

Single value decomposition and global analysis were used to interpret the time course data, which was best fit with a 3-step model $(\mathrm{A} \rightarrow \mathrm{B} \rightarrow \mathrm{C} \rightarrow \mathrm{D})$ with $k_{\mathrm{obs}(1)}$ of $0.2 \mathrm{~s}^{-1}, k_{\mathrm{obs}(2)}$ of $0.01 \mathrm{~s}^{-1}$ and $k_{\mathrm{obs}(3)}$ of $0.004 \mathrm{~s}^{-1}$. The component spectra resulting from this analysis are shown in Fig. S3A. The component A spectrum is consistent with the stopped-flow deadtime spectrum and is assigned as TB14 $\left\{\mathrm{FeO}_{2}\right\}^{8}$. The first phase $(\mathrm{A} \rightarrow \mathrm{B})$ is kinetically well separated from subsequent steps and is complete within $15 \mathrm{~s}$. The absorbance increases in this phase span the 350 to $530 \mathrm{~nm}$ region (Fig. 4C). Calculating the difference spectra of spectral component A minus component B (Fig. S3A, inset) shows features that are consistent with oxidized flavin. ${ }^{68}$ Therefore, this first phase $(A \rightarrow B)$ was assigned to oxidation of the TB144e-red flavin cofactors. The component B spectrum shows the spectrum of TB14 $\left\{\mathrm{FeO}_{2}\right\}^{8}$ with all the flavin cofactors in the reductase domain oxidized. 
The next two phases $(B \rightarrow C$ and $C \rightarrow D)$ are not kinetically well separated, which explains the lack of clear isosbestic points in the time course from 15 to $700 \mathrm{~s}$ (Fig. 4D). The most noticeable changes in the $700 \mathrm{~s}$ time course is an increase in absorbance at $395 \mathrm{~nm}$ and loss of the resolved Q-band at $561 \mathrm{~nm}$. These spectral changes resemble those assigned to TxtE autoxidation (Fig. 3). Additionally, component spectrum C (Fig. S3A) resembles that of L-Trp bound Fe ${ }^{\mathrm{III}} \mathrm{TxtE}$ in the previously discussed time courses. Furthermore, the difference spectrum resulting from subtracting the component B spectrum from component $\mathrm{C}$ is nearly identical to the difference spectrum resulting from subtracting the $1 \mathrm{~s}$ spectrum from the $435 \mathrm{~s}$ spectrum of the $\mathrm{Fe}^{\mathrm{II}} \mathrm{TxtE}$ $\left\{\mathrm{FeO}_{2}\right\}^{8}$ autoxidation time course (Fig. 3B). Therefore, we assign this second phase as autoxidation of the TB14 $\left\{\mathrm{FeO}_{2}\right\}^{8}$ intermediate. Averaging the fitted $k_{\text {obs }}$ for this step across 4 trials gave $k_{\text {autox }}$ of $0.010(0.001) \mathrm{s}^{-1}$, which is similar to $k_{\text {autox }}$ measured observed in the experiments discussed above (Table 1).

The third phase $(C \rightarrow D)$ shows a large and broad increase in absorbance from 300 to $450 \mathrm{~nm}$. The process being reported in this phase is not clear, however there was no corresponding spectral change observed in the TxtE $\left\{\mathrm{FeO}_{2}\right\}^{8}$ autoxidation time courses either in the absence (Fig. 3) or presence of $\mathrm{PdX}_{\text {red }}$ (Figs. 4A and B). This absorbance increase is not in spectral region expected to report $\left\{\mathrm{FeO}_{2}\right\}^{8}$ reduction. In addition, the rate constant for its formation and its stability is inconsistent with the formation of such a reduced intermediate. We conclude that the third phase is not on pathway and speculate this phase is an artifact of using the photodiode array to monitor the reaction. Nevertheless, none of the spectral features in the time course or component spectra suggest formation of a reduced $\left\{\mathrm{FeO}_{2}\right\}^{8}$ species. The combined results above strongly suggest that the $\mathrm{TB} 14\left\{\mathrm{FeO}_{2}\right\}^{8}$ intermediate resists reduction by the reductase domain. 


\begin{tabular}{|c|c|c|}
\hline Condition & $k_{\text {auttox }}\left(\mathrm{s}^{-1}\right)^{\mathrm{a}}$ & Source \\
\hline TxtE + Trp & $0.008(0.001)$ & This work \\
\hline $\operatorname{TxtE}+\operatorname{Trp}\left(+\mathbf{P d} X_{\text {red }}\right)$ & $0.0072(0.0015)$ & This work \\
\hline TxtE -Trp & $3.7(0.3)$ & This work \\
\hline \multirow[t]{2}{*}{ TB14 + Trp } & $0.010(0.001)$ & This work \\
\hline & \multicolumn{2}{|l|}{$k_{\text {on }}\left(M^{-1} \mathrm{~s}^{-1}\right)$} \\
\hline$k_{\text {on }}\left(\mathrm{O}_{2}\right)$ & $4.43(0.03) \times 10^{6}$ & Ref. 1 \\
\hline$k_{\text {on }}(\mathrm{NO})$ & $1.82(0.03) \times 10^{6}$ & Ref. 1 \\
\hline
\end{tabular}

Electron coupling during single-turnover TxtE nitration is efficient

As discussed above, both TxtE and TB14 exhibit poor electron coupling in their nitration reactions -2.4 and $5.3 \%$, respectively. ${ }^{10-11}$ The results up to this point strongly suggest that the $\mathrm{TxtE}\left\{\mathrm{FeO}_{2}\right\}^{8}$ intermediate is recalcitrant to reduction. Therefore, the poor electron coupling cannot be explained by a competition between $\left\{\mathrm{FeO}_{2}\right\}^{8}$ reduction and its reaction with NO. Another possibility is that autoxidation of the $\left\{\mathrm{FeO}_{2}\right\}^{8}$ intermediate kinetically competes with its reaction with NO. To estimate the rate of this latter reaction, sequential-mix stopped-flow UVvis spectrophotometry was used to monitor the reaction of the $\mathrm{TxtE}\left\{\mathrm{FeO}_{2}\right\}^{8}$ intermediate with NO (Fig. 5A). An anaerobic solution of $40 \mu \mathrm{M} \mathrm{Fe}^{\mathrm{II}} \mathrm{TxtE}$ with $1 \mathrm{mM}$ L-Trp was prepared in $\mathrm{pH}$ 8.0 buffer. The spectrum of $\mathrm{Fe}^{\mathrm{II}} \mathrm{TxtE}$ was verified by mixing the protein solution with deoxygenated buffer in both mixing steps and the spectrum was identical to the $\mathrm{Fe}^{\mathrm{II}} \mathrm{TxtE}$ spectrum reported in Fig 3A. The Fe ${ }^{\mathrm{II}} \mathrm{TxtE}$ solution was then mixed at a 1:1 $(v / v)$ ratio with airsaturated buffer in the pre-mix circuit for 1 s to generate the $\left\{\mathrm{FeO}_{2}\right\}^{8}$ intermediate. Next, the solution containing the $\left\{\mathrm{FeO}_{2}\right\}^{8}$ intermediate was mixed at a 1:1 ( $\left.v / v\right)$ ratio with $1200 \mu \mathrm{M}$ NO in 
$100 \mathrm{mM}$ Tris, $\mathrm{pH}$ 8.0. Spectral features of the $\left\{\mathrm{FeO}_{2}\right\}^{8}$ intermediate were not observed in the deadtime spectrum. Instead, the deadtime spectrum exhibited absorbance features with maxima at $365,436,547$, and $578 \mathrm{~nm}$. The time course was consistent with the formation of a heme ferric-nitrosyl species, $\{\text { FeNO }\}^{6}$, within the stopped-flow deadtime of 2 ms. The observation of an $\{\mathrm{FeNO}\}^{6}$ product is best explained by a reaction sequence in which $\mathrm{Fe}^{\mathrm{III}} \mathrm{TxtE}$ is the product of the TxtE $\left\{\mathrm{FeO}_{2}\right\}^{8}$ reaction with NO:

$\left\{\mathrm{FeO}_{2}\right\}^{8}+\mathrm{NO}+\mathrm{L}-\mathrm{Trp} \rightarrow \mathrm{Fe}^{\mathrm{III}}+4-\mathrm{NO}_{2}-\mathrm{L}-\mathrm{Trp}+\mathrm{H}_{2} \mathrm{O}$

$\mathrm{Fe}^{\mathrm{III}}+\mathrm{NO} \rightarrow\{\mathrm{FeNO}\}^{6}$

The high concentration of NO remaining in the experiment after single turnover, promoted its binding to $\mathrm{Fe}^{\mathrm{III}}$ to yield the observed $\{\mathrm{FeNO}\}^{6}$ product. The $k_{\mathrm{obs}}$ for the $\left\{\mathrm{FeO}_{2}\right\}^{8}$ reaction with $\mathrm{NO}$ at $20^{\circ} \mathrm{C}$ was estimated at greater than $1700 \mathrm{~s}^{-1}$, agreeing well with that previously reported. ${ }^{1}$ Of note, the estimated $k_{\text {obs }}$ of this reaction is over 200,000 -fold faster than the TxtE $k_{\text {autox }}$ of 0.008 $\mathrm{S}^{-1}$. These results suggest that the reaction of $\mathrm{NO}$ with $\left\{\mathrm{FeO}_{2}\right\}^{8}$ is far too fast for autoxidation to account for the poor electron coupling observed under turnover conditions.

Another possibility is that uncoupling occurs after the NO reaction with $\left\{\mathrm{FeO}_{2}\right\}^{8}$ by an uncoupling pathway unique to TxtE (or RufO). To test the existence of such uncoupling pathways, we quantified electron coupling efficiency to formation of 4-NO $\mathrm{NO}_{2}-\mathrm{L}-\mathrm{Trp}$ in single-turnover TxtE samples. Anaerobic samples containing $100 \mu \mathrm{M} \mathrm{Fe}^{\mathrm{II}} \mathrm{TxtE}$ and $500 \mu \mathrm{M}$ L-Trp in pH 8.0 buffer were simultaneously exposed to air and $0.9 \mathrm{mM}$ of the $\mathrm{NO}$ generator PROLI-NONOate for 30 minutes at room temperature. For comparison, TB14 steady-state samples contained $0.5 \mu \mathrm{M}$ TB14, $500 \mu \mathrm{M}$ L-Trp, 2 mM NADPH, and 1.33 mM DEA NONOate in 200 mM Tris buffer, pH 8.0, and were incubated at room temperature for 30 minutes. Comparison of the $\mathrm{m} / \mathrm{z} 248.00$ extracted ion chromatograms showed that the $\mathrm{Fe}^{\mathrm{II}} \mathrm{TxtE}$ samples produce significantly more 4-NO2-L-Trp than 
in steady-state TB14 samples (Fig. 5B). Quantitative analysis (Figs. S4 and S5) showed that the $\mathrm{Fe}^{\mathrm{II}} \mathrm{TxtE}$ and steady-state $\mathrm{TB} 14$ samples produce $70 \pm 8 \mu \mathrm{M}$ and $6.3 \pm 0.5 \mu \mathrm{M} 4-\mathrm{NO}_{2}$-L-Trp, respectively (Table 2). Electron coupling efficiency was calculated by dividing the concentration of 4- $\mathrm{NO}_{2}$-L-Trp generated by the concentration of reducing equivalents in the reaction. By this definition, the calculated electron coupling efficiencies for the single-turnover $\mathrm{Fe}^{\mathrm{II}} \mathrm{TxtE}$ and steady-state TB14 samples were $70 \pm 8 \%$ and $0.16 \pm 0.01 \%$, respectively. Therefore, the singleturnover condition exhibits an over 400-fold difference in electron coupling efficiency. The significantly higher electron coupling observed in single-turnover samples suggests that there is little electron uncoupling after the reaction of the $\left\{\mathrm{FeO}_{2}\right\}^{8}$ intermediate and therefore, such an uncoupling pathway does not account for poor coupling observed during steady-state conditions.
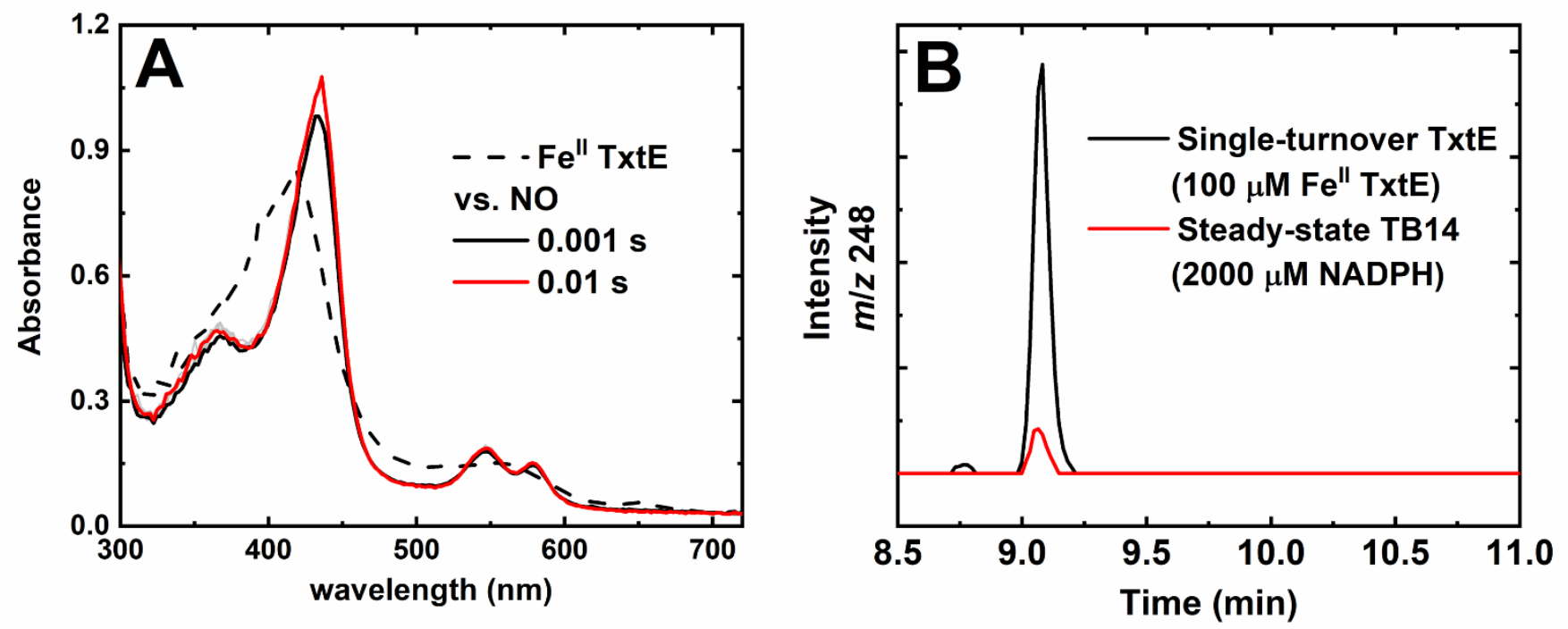

Figure 5. Reaction of $\mathrm{TxtE}\left\{\mathrm{FeO}_{2}\right\}^{8}$ intermediate with NO. Stopped-flow sequential-mix spectral time course of the TxtE $\left\{\mathrm{FeO}_{2}\right\}^{8}$ intermediate vs. NO over $10 \mathrm{~ms}$ at $\mathrm{pH} 8.0$ and $20^{\circ} \mathrm{C}$ (A). Dashed trace is the spectrum of $\mathrm{Fe}^{\mathrm{II}} \mathrm{TxtE}$ acquired from mixing $\mathrm{Fe}^{\mathrm{II}} \mathrm{TxtE}$ with deoxygenated buffer in both mix steps. Conditions after stopped-flow mixing: $10 \mu \mathrm{M} \mathrm{Fe}{ }^{\mathrm{II}} \mathrm{TxtE}$, $250 \mu \mathrm{M}$ L-Trp, $70 \mu \mathrm{M} \mathrm{O}_{2}$, and $600 \mu \mathrm{M} \mathrm{NO}$ in $100 \mathrm{mM}$ Tris, $\mathrm{pH} 8.0$ at $20^{\circ} \mathrm{C}$ in a $1 \mathrm{~cm}$ path length cuvette. Extracted ion LC-MS chromatograms monitoring $\mathrm{m} / \mathrm{z} 248.00$ (B) of 
representative $\mathrm{Fe}^{\mathrm{II}} \mathrm{TxtE}$ single turnover samples (black trace) or TB14 turnover samples (red trace). Conditions after mixing: $100 \mu \mathrm{M} \mathrm{Fe} \mathrm{Fe}^{\mathrm{II}} \mathrm{TxtE}, 500 \mu \mathrm{M}$ L-Trp, $0.9 \mathrm{mM}$ PROLI-NONOate in $200 \mathrm{mM}$ Tris, pH 8.0 (black trace) and $0.5 \mu \mathrm{M}$ TB14, $500 \mu \mathrm{M}$ L-Trp, 2 mM NADPH, and 1.33 mM DEA NONOate in $200 \mathrm{mM}$ Tris buffer, pH 8.0 (red trace). Samples were incubated at room temperature for 30 minutes prior to analysis.

To verify that the $\left\{\mathrm{FeO}_{2}\right\}^{8}$ intermediate is resistant to reduction, we measured the electron coupling of one- (TB141e-red), two- (TB142e-red), and four- (TB1444-red) electron reduced TB14. Anaerobic samples of $20 \mu \mathrm{M}$ TB14 and $500 \mu \mathrm{M}$ L-Trp in pH 8.0 buffer were reduced with either 10 (TB141e-red), 20 (TB142e-red), or $40 \mu \mathrm{M}$ (TB144e-red) NADPH. The samples were incubated for 30 minutes at room temperature to ensure complete transfer of reducing equivalents from NADPH to TB14. Nitration of L-Trp was initiated by exposing these reduced samples simultaneously to 1 mM PROLI-NONOate and air. Quantitative analysis of these samples by HPLC showed that the TB1414-red, TB142e-red, and TB14 4 -red samples generated $0.58 \pm 0.02,2.4 \pm 0.8$, and $4.7 \pm 0.8 \mu \mathrm{M}$ 4-NO $\mathrm{N}_{2}$-L-Trp, respectively (Table 2 and Fig. S6). The calculated electron coupling efficiency for the TB14 1 e-red samples was $2.9 \pm 0.1 \%$, which was 18 -fold higher than that for the TB14 steadystate samples, indicating again that uncoupling is less severe in single-turnover conditions. The TB14 $4_{2 \text {-red }}$ and TB144e-red samples exhibited $6.1 \pm 1.9 \%$ and $6.0 \pm 1.0 \%$ electron coupling efficiencies, respectively, which are both 2-fold higher than the TB141e-red sample. Reduction of the $\left\{\mathrm{FeO}_{2}\right\}^{8}$ intermediate to $\left\{\mathrm{FeO}_{2}\right\}^{9}$ would be expected to result in either uncoupling to form $\mathrm{H}_{2} \mathrm{O}_{2}$ or subsequent protonation of the intermediate followed by L-Trp hydroxylation. In either event, reduction of the $\left\{\mathrm{FeO}_{2}\right\}^{8}$ intermediate would be expected to result in a decrease, not an increase, in electron coupling efficiency. The electron coupling efficiencies observed for these TB14 experiments are consistent with our conclusion that the $\left\{\mathrm{FeO}_{2}\right\}^{8}$ resists reduction. 
Table 2. Electron coupling efficiencies for single- and steady-state nitration turnover of TxtE and TB14

\section{[4-NO2-L-Trp]}

\begin{tabular}{|c|c|c|c|}
\hline Condition & $(\mu \mathrm{M})^{\mathrm{a}}$ & R.E. $(\mu \mathrm{M})^{\mathrm{b}}$ & Coupling efficiency (\%) \\
\hline $\mathrm{Fe}^{\mathrm{II}} \mathrm{TxtE}^{\mathrm{d}}$ & $70(8)$ & 100 & $70(7)$ \\
\hline TB141e-red $^{\mathrm{e}}$ & $0.58(0.02)$ & 20 & $2.9(0.1)$ \\
\hline TB142e-red $^{\mathrm{e}}$ & $2.4(0.8)$ & 40 & $6.1(1.9)$ \\
\hline TB144e-red $^{\mathrm{e}}$ & $4.7(0.8)$ & 80 & $6.0(1.0)$ \\
\hline TB14 steady-state $\mathrm{f}$ & $6.3(0.5)$ & 4000 & $0.16(0.01)$ \\
\hline
\end{tabular}

${ }^{\mathrm{a}}$ Average of 3 trials; standard deviation reported in parentheses.

${ }^{\mathrm{b}}$ Reducing equivalents (R.E.)

${ }^{\mathrm{c}}$ Calculated as $\left[4-\mathrm{NO}_{2}\right.$-L-Trp]/[reducing equivalents]

${ }^{\mathrm{d}}$ Reaction conditions: $100 \mu \mathrm{M}$ Fe ${ }^{\mathrm{II}} \mathrm{TxtE}, 500 \mu \mathrm{M}$ L-Trp, $0.86 \mathrm{mM}$ PROLI-NONOate in pH 8.0 buffer.

${ }^{\text {e}}$ Reaction conditions: $20 \mu \mathrm{M}$ TB14, 0.5 mM L-Trp, and 1 mM PROLI-NONOate in pH 8.0 buffer with either 10 (TB14 1 e-red), 20 (TB14 2 e-red), or $40 \mu \mathrm{M}$ (TB14 $4 \mathrm{e}$-red $)$ NADPH.

${ }^{\mathrm{f}}$ Reaction conditions: $0.5 \mu \mathrm{M}$ TB14, $500 \mu \mathrm{M}$ L-Trp, $2 \mathrm{mM}$ NADPH, and $1.33 \mathrm{mM}$ DEANONOate ( $2 \mathrm{mM} \mathrm{NO}$ ) in $\mathrm{pH} 8.0$ buffer.

\section{Discussion}

A central objective of this work was to characterize the lifetime of the TxtE $\left\{\mathrm{FeO}_{2}\right\}^{8}$ intermediate in the absence and presence of NO. Our results are consistent with formation of an $\left\{\mathrm{FeO}_{2}\right\}^{8}$ intermediate upon reaction of $\mathrm{Fe}^{\mathrm{II}} \mathrm{TxtE}$ with $\mathrm{O}_{2}$ (Fig. 3). This intermediate decays over several minutes by autoxidation to regenerate the Fe ${ }^{\mathrm{III}} \mathrm{TxtE}$ (Table 1). In the presence of excess NO, the $\left\{\mathrm{FeO}_{2}\right\}^{8}$ decays rapidly, leaving spectroscopic evidence for formation of a heme $\{\mathrm{FeNO}\}^{6}$ species. The results are consistent with the TxtE $\left\{\mathrm{FeO}_{2}\right\}^{8}$ intermediates reacting with NO to rapidly form 
$\mathrm{Fe}^{\mathrm{III}} \mathrm{TxtE}$. The observation of $\{\mathrm{FeNO}\}^{6}$ resulted from the reaction of the excess NO with the Fe $\mathrm{F}^{\mathrm{III}}$ TxtE (Fig. 6). Our stopped-flow time course is consistent with data recently presented on the TxtE mechanism. ${ }^{1}$ Louka, et al. interpreted this observation as $\left\{\mathrm{FeO}_{2}\right\}^{8}$ reacting with $\mathrm{NO}$ to form a putative $\mathrm{Fe}^{\mathrm{III}}$-OONO intermediate as summarized on the right side of Fig. 6. The authors also presented computational data suggesting a pathway in which homolytic cleavage of the $\mathrm{O}-\mathrm{O}$ bond results in formation of a ferryl intermediate and ${ }^{\circ} \mathrm{NO}_{2}$. Together these species were proposed to mediate the nitration of L-Trp.

In addition to characterizing the mechanism of the direct nitration reaction of TxtE, we conclude that the TxtE $\left\{\mathrm{FeO}_{2}\right\}^{8}$ intermediate resists reduction. Samples of TxtE and TB14 samples directly supplemented with $\mathrm{H}_{2} \mathrm{O}_{2}$ and L-Trp clearly showed the presence of L-Trp-OH (Fig. 2). This observation is consistent with TxtE accessing L-Trp hydroxylation by the peroxide shunt pathway (Fig. 1). Furthermore, L-Trp-OH was observed in TB14 $\mathrm{O}_{2}$-turnover samples but not in parallel samples containing the $\mathrm{H}_{2} \mathrm{O}_{2}$ scavenger catalase. Together, these results strongly suggest that critical intermediates for hydroxylation are not accessible during $\mathrm{O}_{2}$-turnover conditions (Fig. 6). First, the observation of L-Trp-OH in peroxide shunt conditions indicated that TxtE can bind $\mathrm{H}_{2} \mathrm{O}_{2}$ to generate the $\mathrm{Fe}{ }^{\mathrm{III}}-\mathrm{OOH}$ species and eventually form compound I competent for L-Trp hydroxylation. Second, the lack of L-Trp-OH when diffusible $\mathrm{H}_{2} \mathrm{O}_{2}$ was scavenged strongly suggests that TxtE is incapable of either reducing the $\left\{\mathrm{FeO}_{2}\right\}^{8}$ intermediate to $\left\{\mathrm{FeO}_{2}\right\}^{9}$ or alternatively, protonating this latter species to form $\mathrm{Fe}^{\mathrm{III}}-\mathrm{OOH}$. Thus, TxtE avoids entering the canonical CYP pathway towards hydroxylation.

Supporting this conclusion, the time courses monitoring the decay of the $\left\{\mathrm{FeO}_{2}\right\}^{8}$ intermediate (Fig. 4) in the presence of reduced CYP ET partners lacked any spectroscopic or kinetic evidence for the formation of $\left\{\mathrm{FeO}_{2}\right\}^{9}$ or $\mathrm{Fe} \mathrm{F}^{\mathrm{III}}-\mathrm{OOH}$. Indeed, other than accumulation of spectroscopic 
features related to oxidation of the ET partners, the time courses closely resembled that of autoxidation of TxtE (Fig. 3). Furthermore, increasing the number of reducing equivalents in TB14 had no detrimental effect on electron coupling (Table 2), contrary to what would be expected in the $\left\{\mathrm{FeO}_{2}\right\}^{8}$ intermediate could be reduced (Fig. 6). Our accumulated results frongly suggest that the TxtE $\left\{\mathrm{FeO}_{2}\right\}^{8}$ intermediate resists reduction.

The recalcitrance of the TxtE $\left\{\mathrm{FeO}_{2}\right\}^{8}$ intermediate is critical for its nitration activity. If TxtE $\left\{\mathrm{FeO}_{2}\right\}^{8}$ could be either reduced or reacted with NO, the two pathways would compete for the fate of L-Trp to form the hydroxylated product, L-Trp-OH or the nitrated product 4- $\mathrm{NO}_{2}$-L-Trp (Fig. 6). The resulting product distributions can be estimated using reduction rate constants from CYP101A1. For this enzyme, the reduction of $\left\{\mathrm{FeO}_{2}\right\}^{8}$ is rapid with a rate constant of 85 to 140 $\mathrm{s}^{-1}$ at 3-4 ${ }^{\circ} \mathrm{C} .{ }^{65-67}$ The NO reaction with TxtE $\left\{\mathrm{FeO}_{2}\right\}^{8}$ reported by Louka, et al. was also performed at $4{ }^{\circ} \mathrm{C}$ and was complete within $100 \mathrm{~ms}$. This provides an estimate of the $k_{\mathrm{obs}}$ for the NO reaction with TxtE $\left\{\mathrm{FeO}_{2}\right\}^{8}$ as $35 \mathrm{~s}^{-1}$ at $4{ }^{\circ} \mathrm{C}$. Under these conditions, hydroxylation of L-Trp would outcompete its nitration by a 2:1 ratio. Therefore, the ability of TxtE to resist $\left\{\mathrm{FeO}_{2}\right\}^{8}$ reduction appears to greatly improve the efficiency of the enzyme for the nitration by avoiding hydroxylation. Another consequence is that the lifetime of the $\left\{\mathrm{FeO}_{2}\right\}^{8}$ intermediate is increased, thereby facilitating its bimolecular reaction with NO for the nitration. 


\section{L-Trp hydroxylation}

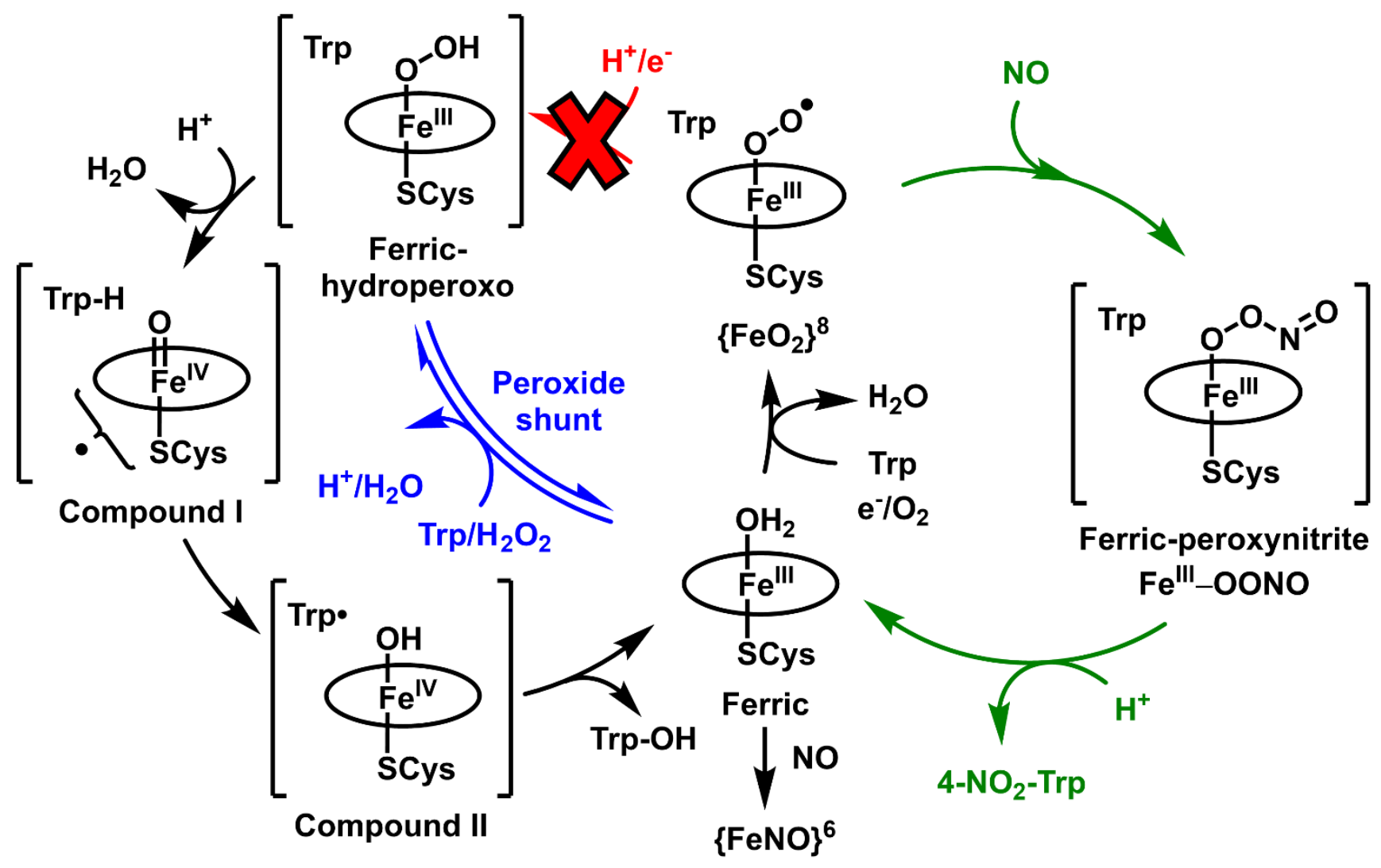

Figure 6. Proposed TxtE hydroxylation pathway by the peroxide shunt and NO-dependent nitration pathway. Brackets surround proposed intermediates not yet characterized for TxtE.

Comparison of the TxtE crystal structure to that of CYP101A1 may provide some structurefunction clues to our observations. Two key residues in CYP101A1, D251 and T252, sometimes referred to as the acid-alcohol pair, are critical for its hydroxylation activity (Fig. 7, left panel). A key role of the $\mathrm{T} 252$ residue is to promote the protonation of the $\mathrm{Fe} \mathrm{e}^{\mathrm{III}}-\mathrm{OOH}$ to form compound I. A T252A variant of CYP101A1 greatly hinders electron coupling as evidenced by both a lower ratio of mol product formation per mol NADH consumed and a marked increase in $\mathrm{H}_{2} \mathrm{O}_{2}$ production. ${ }^{69-70}$ This has been attributed to uncoupling of $\mathrm{H}_{2} \mathrm{O}_{2}$ from the $\mathrm{Fe}{ }^{\mathrm{III}}-\mathrm{OOH}$ intermediate 
due to slowed proton transfer. The role of D251 is to promote a critical conformation change in the CYP101A1 I helix that allows for orienting catalytic waters near the active site upon $\mathrm{O}_{2}$ binding. ${ }^{71-73}$ Formation of a D251N CYP101A1 variant exhibited a far decreased rate of NADH consumption. This was attributed to the absence of the catalytic water residues that inhibited reduction of the $\left\{\mathrm{FeO}_{2}\right\}^{8}$ intermediate. The TxtE crystal structure shows that in the place of the acid alcohol pair of CYP101A are the P249 and T250 residues (Fig. 7, right panel). Therefore, the threonine residue remains, but proline replaces the acid residue of CYP101A. The presence of the homologous Thr may explain why TxtE can hydroxylate L-Trp by the peroxide shunt because upon binding of $\mathrm{H}_{2} \mathrm{O}_{2}$ to the $\mathrm{Fe}^{\mathrm{III}} \mathrm{TxtE}$ to form the $\mathrm{Fe}^{\mathrm{III}}-\mathrm{OOH}$ intermediate, the Thr is available to promote protonation and conversion of this intermediate to compound I (Fig. 6). Meanwhile, TxtE lacks D251 as well as other residues, such as N255, needed to support the confirmation change of the I-helix. With P249 in this position it is likely that the ordered waters will be different compared to that of CYP101A1, which may account for the observed resistance of the TxtE $\left\{\mathrm{FeO}_{2}\right\}^{8}$ intermediate to reduction.

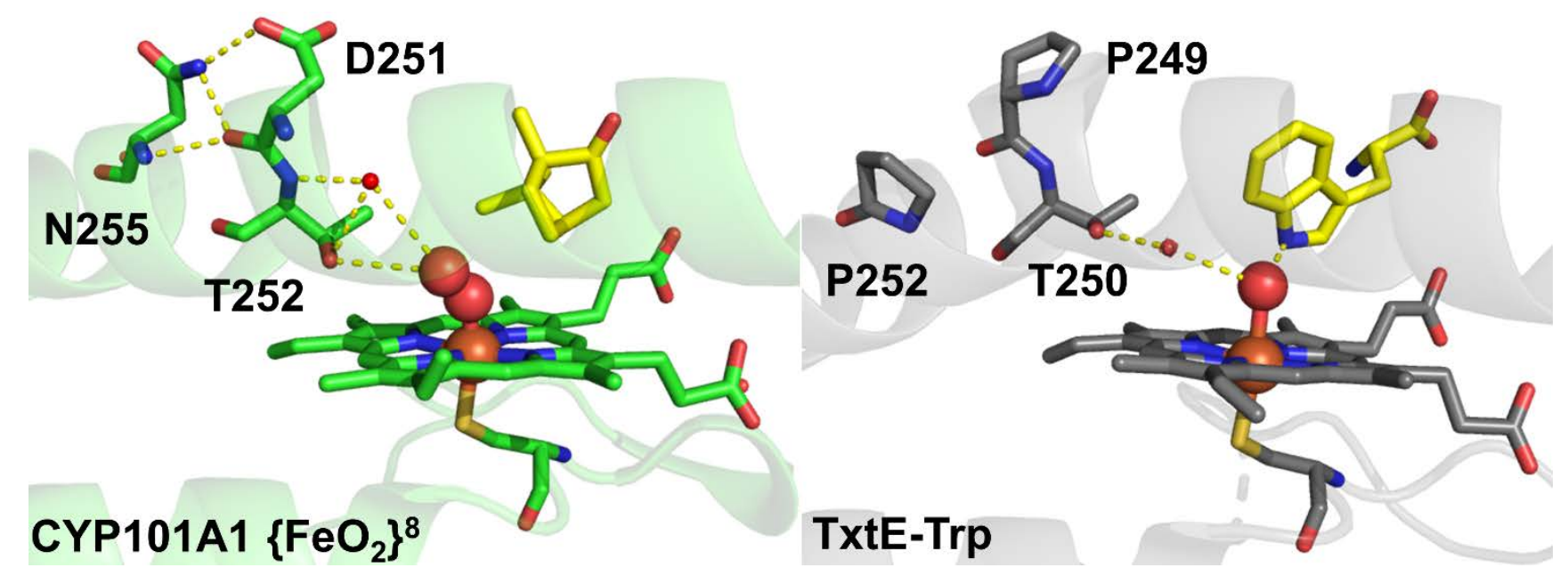


Figure 7. Crystal structures of CYP101A1 $\left\{\mathrm{FeO}_{2}\right\}^{8}$ intermediate (PDB: 1DZ8) and L-Trp bound $\mathrm{Fe}^{\mathrm{III}}$ TxtE (PDB: 4TPO). Carbon atoms are colored green for CYPP101A1 and gray for TxtE, oxygen atoms are red, nitrogen atoms are dark blue, sulfur atoms are yellow, iron atom is orange. H-bonds demarcated by dashed yellow lines.

Finally, some of our results may also help to explain the poor coupling efficiencies observed during TxtE and TB14 turnovers. As discussed above, the inability of the $\mathrm{TxtE}\left\{\mathrm{FeO}_{2}\right\}^{8}$ intermediate to be reduced avoids formation of L-Trp-OH in place of 4- $\mathrm{NO}_{2}$-L-Trp. In addition, TxtE avoids formation of either $\left\{\mathrm{FeO}_{2}\right\}^{9}$ or $\mathrm{Fe}^{\mathrm{III}}-\mathrm{OOH}$, which precludes generation of a $\mathrm{H}_{2} \mathrm{O}_{2}$ equivalent from uncoupling of these intermediates. Another possibility is that TxtE possesses a unique uncoupling pathway. For example, the putative Fe $\mathrm{III}^{\mathrm{II}} \mathrm{OONO}$ has been proposed by Louka, et al. to decay to a ferryl intermediate and $\bullet \mathrm{NO}_{2}$, which together can be the direct nitration agents of L-Trp. The decay of Fe ${ }^{\mathrm{III}}$-OONO to similar species has also been proposed for the reaction of hemoglobin with $\mathrm{ONOO}^{-}$and for the mechanism of the $\mathrm{NO}$ dioxygenase enzyme flavohemoglobin. ${ }^{45-47}$ The product of both of these reactions is nitrate $\left(\mathrm{NO}_{3}{ }^{-}\right)$. In such a way, a TxtE uncoupling pathway resulting in unproductive coupling of electrons to form $\mathrm{NO}_{3}{ }^{-}$can be envisioned. However, single-turnover nitration samples of TxtE show excellent coupling efficiency (70 $\pm 8 \%$ ), 400-fold higher than the steady-state turnover samples (Fig. 5B and Table 2). Electron coupling efficiencies for TB14 were previously reported as $5.3 \pm 0.5 \% \mathrm{~mol} 4-\mathrm{NO}_{2}$ L-Trp per mol NADPH consumed when a relatively stable NO donor, NOC-5, was used. ${ }^{11}$ This calculates to $2.7 \%$ mol product per mol reducing equivalent. On this basis, electron coupling by TxtE under a single-turnover nitration conditions exceeds that for reported TB14 steady-state 
turnover by over 25-fold. This much improved electron coupling efficiency appears to rule out an uncoupling pathway originating from the putative $\mathrm{Fe}^{\mathrm{III}}-\mathrm{OONO}$ intermediate.

We can rule out all of the uncoupling pathways for TxtE except the autoxidation pathway. By monitoring the reaction of TxtE $\left\{\mathrm{FeO}_{2}\right\}^{8}$ with NO, we estimated the $k_{\text {obs }}$ for the $\left\{\mathrm{FeO}_{2}\right\}^{8}$ reaction with NO as greater than $1700 \mathrm{~s}^{-1}$. This $k_{\text {obs }}$ value is over 200,000 -fold faster than autoxidation of $\mathrm{TxtE}\left\{\mathrm{FeO}_{2}\right\}^{8}\left(0.008 \mathrm{~s}^{-1}\right)$. Therefore, uncoupling by autoxidation will not compete under steadystate nitration turnover if there is sufficient NO present. However, when the steady-state NO concentration is low, $\mathrm{TxtE}\left\{\mathrm{FeO}_{2}\right\}^{8}$ autoxidation can outcompete the reaction with NO. Therefore, the poor electron coupling efficiencies most likely result from insufficient NO delivery rates by the NO generators used in our in vitro experiments. If decay of the NO generator is too slow to consume the TxtE $\left\{\mathrm{FeO}_{2}\right\}^{8}$ intermediate, the intermediate will decay by autoxidation instead. Improvements in the in vitro efficiency of TxtE or its variants is expected in the presence of an NO donor that matches better with the lifetime of the $\left\{\mathrm{FeO}_{2}\right\}^{8}$ intermediate. For in vivo considerations, the delivery of NO by bNOS is critical to balance efficient nitration with overproduction of $\mathrm{NO}$ that can 1) scavenge $\mathrm{O}_{2}$, a necessary co-substrate for nitration and 2) be lethal to the cell at high concentrations.

\title{
ASSOCIATED CONTENT
}

Supporting Information. Supporting figures discussed in the text are given (PDF).

\author{
AUTHOR INFORMATION
}

\section{Corresponding Author}


Jonathan D. Caranto - Department of Chemistry, University of Central Florida, 4111 Libra

Dr., Room 255, Orlando, FL 32816; orcid.org/0000-0002-9196-5275; Email:

jonathan.caranto@ucf.edu

Yousong Ding - Department of Medicinal Chemistry, Center for Natural Products, Drug

Discovery and Development, University of Florida, 1345 Center Dr., Room P6-27, Gainesville,

FL 32610; Email: YDing@cop.ufl.edu

Present Addresses

Christopher P. Martin - Department of Chemistry, University of Central Florida, 4111 Libra

Dr., Room 255, Orlando, FL 32816

Manyun Chen - Department of Medicinal Chemistry, Center for Natural Products, Drug

Discovery and Development, University of Florida, 1345 Center Dr., Room P6-27, Gainesville,

FL 32610

Maria F. Martinez - Department of Chemistry, University of Central Florida, 4111 Libra Dr., Room 255, Orlando, FL 32816

Rosemary Loria - Department of Plant Pathology, University of Florida, 2550 Hull Road, PO Box 110680, Gainesville, FL 32611

\section{Author Contributions}

The manuscript was written through contributions of all authors. All authors have given approval to the final version of the manuscript. 


\title{
Notes
}

The authors declare no competing financial interest.

\section{ACKNOWLEDGMENTS}

J.D.C. thanks the UCF College of Sciences and Department of Chemistry for the funding for this project. We also thank Dr. Matthew Rex and Bhavini Goswami for their assistance in LC-MS.

\begin{abstract}
ABBREVIATIONS
NO, nitric oxide; ET, electron transfer; L-Trp, L-tryptophan; bNOS, bacterial nitric oxide synthase; L-Trp-OH, hydroxy-L-tryptophan; 4-NO2-L-Trp, 4-nitro-L-tryptophan; 5-ALA, 5-aminolevulinic acid; PMSF, phenylmethylsulfonyl fluoride; LC-MS, liquid chromatography couple mass spectrometry; HPLC, high performance liquid chromatography; PROLI-NONOate, 1-(hydroxyNNO-azoxy)-L-proline; DEA-NONOate, Diethylammonium (Z)-1-(N,N-diethylamino)diazen-1ium-1,2-diolate; NADPH, nicotinamide adenine dinucleotide phosphate; NADH, nicotinamide adenine dinucleotide; PdX, putidaredoxin.
\end{abstract}

\section{REFERENCES}

1. $\quad$ Louka, S.; Barry, S. M.; Heyes, D. J.; Mubarak, M. Q. E.; Ali, H. S.; Alkhalaf, L.; Munro, A. W.; Scrutton, N. S.; Challis, G. L.; de Visser, S. P., The catalytic mechanism of aromatic nitration by cytochrome P450 TxtE: Involvement of a ferric-peroxynitrite intermediate. J. Am. Chem. Soc. 2020.

2. Nelson, D. R., Cytochrome P450 diversity in the tree of life. Biochim. Biophys. Acta Proteins and Proteom. 2018, 1866 (1), 141-154.

3. Guengerich, F. P.; Munro, A. W., Unusual cytochrome P450 enzymes and reactions. $J$. Biol. Chem. 2013, 288 (24), 17065-17073.

4. Barry, S. M.; Kers, J. A.; Johnson, E. G.; Song, L.; Aston, P. R.; Patel, B.; Krasnoff, S. B.; Crane, B. R.; Gibson, D. M.; Loria, R., Cytochrome P450-catalyzed L-tryptophan nitration in thaxtomin phytotoxin biosynthesis. Nat. Chem. Biol. 2012, 8 (10), 814-816.

5. Tomita, H.; Katsuyama, Y.; Minami, H.; Ohnishi, Y., Identification and characterization of a bacterial cytochrome P450 monooxygenase catalyzing the 3-nitration of tyrosine in rufomycin biosynthesis. J. Biol. Chem. 2017, 292 (38), 15859-15869. 
6. Tsutsumi, H.; Katsuyama, Y.; Izumikawa, M.; Takagi, M.; Fujie, M.; Satoh, N.; Shin-Ya, K.; Ohnishi, Y., Unprecedented cyclization catalyzed by a cytochrome P450 in benzastatin biosynthesis. J. Am. Chem. Soc. 2018, 140 (21), 6631-6639.

7. $\quad$ Rylott, E. L.; Jackson, R. G.; Sabbadin, F.; Seth-Smith, H. M.; Edwards, J.; Chong, C. S.; Strand, S. E.; Grogan, G.; Bruce, N. C., The explosive-degrading cytochrome P450 XplA: biochemistry, structural features and prospects for bioremediation. Biochim. Biophys. Acta Proteins and Proteom. 2011, 1814 (1), 230-236.

8. Dodani, S. C.; Cahn, J. K.; Heinisch, T.; Brinkmann - Chen, S.; McIntosh, J. A.; Arnold, F. H., Structural, functional, and spectroscopic characterization of the substrate scope of the novel nitrating cytochrome P450 TxtE. ChemBioChem 2014, 15 (15), 2259-2267.

9. $\quad$ Dodani, S. C.; Kiss, G.; Cahn, J. K.; Su, Y.; Pande, V. S.; Arnold, F. H., Discovery of a regioselectivity switch in nitrating P450s guided by molecular dynamics simulations and Markov models. Nat. Chem. 2016, 8 (5), 419.

10. Zuo, R.; Zhang, Y.; Huguet - Tapia, J. C.; Mehta, M.; Dedic, E.; Bruner, S. D.; Loria, R.;

Ding, Y., An artificial self - sufficient cytochrome P450 directly nitrates fluorinated tryptophan analogs with a different regio - selectivity. Biotechnol. J. 2016, 11 (5), 624-632.

11. Zuo, R.; Zhang, Y.; Jiang, C.; Hackett, J. C.; Loria, R.; Bruner, S. D.; Ding, Y., Engineered $\mathrm{P} 450$ biocatalysts show improved activity and regio-promiscuity in aromatic nitration. Sci. Rep. 2017, 7 (1), 842.

12. Jiang, G.; Zhang, Y.; Powell, M. M.; Zhang, P.; Zuo, R.; Zhang, Y.; Kallifidas, D.; Tieu, A. M.; Luesch, H.; Loria, R., High-yield production of herbicidal thaxtomins and thaxtomin analogs in a nonpathogenic Streptomyces strain. Appl. Environ. Microbiol. 2018, 84 (11).

13. Loria, R.; Bignell, D. R.; Moll, S.; Huguet-Tapia, J. C.; Joshi, M. V.; Johnson, E. G.; Seipke, R. F.; Gibson, D. M., Thaxtomin biosynthesis: the path to plant pathogenicity in the genus Streptomyces. Antonie Van Leeuwenhoek 2008, 94 (1), 3-10.

14. Loria, R.; Bukhalid, R. A.; Fry, B. A.; King, R. R., Plant pathogenicity in the genus Streptomyces. Plant Dis. 1997, 81 (8), 836-846.

15. King, R. R.; Calhoun, L. A., The thaxtomin phytotoxins: sources, synthesis, biosynthesis, biotransformation and biological activity. Phytochemistry 2009, 70 (7), 833-841.

16. King, R. R.; Lawrence, C. H.; Calhoun, L. A., Chemistry of phytotoxins associated with Streptomyces scabies the causal organism of potato common scab. J. Agric. Food. Chem. 1992, 40 (5), 834-837.

17. $\quad$ King, R. R.; Lawrence, C. H.; Clark, M. C.; Calhoun, L. A., Isolation and characterization of phytotoxins associated with Streptomyces scabies. J. Chem. Soc., Chem. Commun. 1989, 0 (13), 849-850.

18. Kers, J. A.; Cameron, K. D.; Joshi, M. V.; Bukhalid, R. A.; Morello, J. E.; Wach, M. J.; Gibson, D. M.; Loria, R., A large, mobile pathogenicity island confers plant pathogenicity on Streptomyces species. Mol. Microbiol. 2005, 55 (4), 1025-1033.

19. Zhang, Y.; Loria, R., Emergence of novel pathogenic Streptomyces species by sitespecific accretion and cis-mobilization of pathogenicity islands. Mol. Plant-Microbe Interact. 2017, 30 (1), 72-82.

20. Scheible, W.-R.; Fry, B.; Kochevenko, A.; Schindelasch, D.; Zimmerli, L.; Somerville, S.; Loria, R.; Somerville, C. R., An Arabidopsis mutant resistant to thaxtomin A, a cellulose synthesis inhibitor from Streptomyces species. Plant Cell 2003, 15 (8), 1781-1794. 
21. Healy, F. G.; Wach, M.; Krasnoff, S. B.; Gibson, D. M.; Loria, R., The txtAB genes of the plant pathogen Streptomyces acidiscabies encode a peptide synthetase required for phytotoxin thaxtomin A production and pathogenicity. Mol. Microbiol. 2000, 38 (4), 794-804. 22. Kers, J. A.; Wach, M. J.; Krasnoff, S. B.; Widom, J.; Cameron, K. D.; Bukhalid, R. A.; Gibson, D. M.; Crane, B. R.; Loria, R., Nitration of a peptide phytotoxin by bacterial nitric oxide synthase. Nature 2004, 429 (6987), 79-82.

23. Crane, B. R.; Sudhamsu, J.; Patel, B. A., Bacterial nitric oxide synthases. Annu. Rev. Biochem 2010, 79, 445-470.

24. Wach, M. J.; Kers, J. A.; Krasnoff, S. B.; Loria, R.; Gibson, D. M., Nitric oxide synthase inhibitors and nitric oxide donors modulate the biosynthesis of thaxtomin A, a nitrated phytotoxin produced by Streptomyces spp. Nitric Oxide 2005, 12 (1), 46-53.

25. Tomita, H.; Katsuyama, Y.; Minami, H.; Ohnishi, Y., Identification and characterization of a bacterial cytochrome P450 monooxygenase catalyzing the 3-nitration of tyrosine in rufomycin biosynthesis. J. Biol. Chem. 2017, 292, 15859-15869.

26. Yosca, T. H.; Ledray, A. P.; Ngo, J.; Green, M. T., A new look at the role of thiolate ligation in cytochrome P450. J. Biol. Inorg. Chem. 2017, 22 (2-3), 209-220.

27. Denisov, I. G.; Makris, T. M.; Sligar, S. G.; Schlichting, I., Structure and chemistry of cytochrome P450. Chem. Rev. 2005, 105 (6), 2253-2278.

28. Guengerich, F. P., Mechanisms of cytochrome P450-catalyzed oxidations. ACS catalysis 2018, 8 (12), 10964-10976.

29. Sligar, S. G.; Makris, T. M.; Denisov, I. G., Thirty years of microbial P450

monooxygenase research: peroxo-heme intermediates - the central bus station in heme oxygenase catalysis. Biochem. Biophys. Res. Commun. 2005, 338 (1), 346-354.

30. Enemark, J.; Feltham, R., Principles of structure, bonding, and reactivity for metal nitrosyl complexes. Coord. Chem. Rev. 1974, 13 (4), 339-406.

31. Munro, A. W.; McLean, K. J.; Grant, J. L.; Makris, T. M., Structure and function of the cytochrome P450 peroxygenase enzymes. Biochem. Soc. Trans. 2018, 46 (1), 183-196.

32. Beckman, J. S.; Koppenol, W. H., Nitric oxide, superoxide, and peroxynitrite: the good, the bad, and ugly. Am. J. Physiol. Cell Physiol. 1996, 271 (5), C1424-C1437.

33. Ferrer-Sueta, G.; Campolo, N.; Trujillo, M.; Bartesaghi, S.; Carballal, S. n.; Romero, N.; Alvarez, B.; Radi, R., Biochemistry of peroxynitrite and protein tyrosine nitration. Chem. Rev. 2018, 118 (3), 1338-1408.

34. Cassina, A. M.; Hodara, R.; Souza, J. M.; Thomson, L.; Castro, L.; Ischiropoulos, H.; Freeman, B. A.; Radi, R., Cytochrome c nitration by peroxynitrite. J. Biol. Chem. 2000, 275 (28), 21409-21415.

35. Nakamura, T.; Lipton, S., Molecular mechanisms of nitrosative stress-mediated protein misfolding in neurodegenerative diseases. Cell. Mol. Life Sci. 2007, 64 (13), 1609-1620.

36. Radi, R., Protein tyrosine nitration: biochemical mechanisms and structural basis of functional effects. Acc. Chem. Res. 2012, 46 (2), 550-559.

37. Goldstein, S.; Lind, J.; Merényi, G., Chemistry of peroxynitrites as compared to peroxynitrates. Chem. Rev. 2005, 105 (6), 2457-2470.

38. Nuriel, T.; Hansler, A.; Gross, S. S., Protein nitrotryptophan: formation, significance and identification. J. Proteom. 2011, 74 (11), 2300-2312.

39. Brennan, M.-L.; Wu, W.; Fu, X.; Shen, Z.; Song, W.; Frost, H.; Vadseth, C.; Narine, L.; Lenkiewicz, E.; Borchers, M. T., A tale of two controversies defining both the role of peroxidases in nitrotyrosine formation in vivo using eosinophil peroxidase and myeloperoxidase- 
deficient mice, and the nature of peroxidase-generated reactive nitrogen species. J. Biol. Chem. 2002, 277 (20), 17415-17427.

40. Sampson, J. B.; Ye, Y.; Rosen, H.; Beckman, J. S., Myeloperoxidase and horseradish peroxidase catalyze tyrosine nitration in proteins from nitrite and hydrogen peroxide. Arch. Biochem. Biophys. 1998, 356 (2), 207-213.

41. Herold, S., Nitrotyrosine, dityrosine, and nitrotryptophan formation from metmyoglobin, hydrogen peroxide, and nitrite. Free Radical Biol. Med. 2004, 36 (5), 565-579.

42. Kilinc, K.; Kilinc, A.; Wolf, R. E.; Grisham, M. B., Myoglobin-catalyzed tyrosine nitration: no need for peroxynitrite. Biochem. Biophys. Res. Commun. 2001, 285 (2), 273-276.

43. Grzelak, A.; Balcerczyk, A.; Mateja, A.; Bartosz, G., Hemoglobin can nitrate itself and other proteins. Biochimica et Biophysica Acta (BBA)-General Subjects 2001, 1528 (2-3), 97-100.

44. Thomas, D. D.; Espey, M. G.; Vitek, M. P.; Miranda, K. M.; Wink, D. A., Protein nitration is mediated by heme and free metals through Fenton-type chemistry: An alternative to the NO/O reaction. Proc. Natl. Acad. Sci. U.S.A. 2002, 99 (20), 12691-12696.

45. Su, J.; Groves, J. T., Direct detection of the oxygen rebound intermediates, ferryl Mb and NO2, in the reaction of metmyoglobin with peroxynitrite. J. Am. Chem. Soc. 2009, 131 (36), 12979-12988.

46. Su, J.; Groves, J. T., Mechanisms of peroxynitrite interactions with heme proteins. Inorg. Chem. 2010, 49 (14), 6317-6329.

47. Gardner, P. R., Nitric oxide dioxygenase function and mechanism of flavohemoglobin, hemoglobin, myoglobin and their associated reductases. J. Inorg. Biochem. 2005, 99 (1), 247266.

48. Cao, R.; Elrod, L. T.; Lehane, R. L.; Kim, E.; Karlin, K. D., A Peroxynitrite Dicopper Complex: Formation via $\mathrm{Cu}-\mathrm{NO}$ and $\mathrm{Cu}-\mathrm{O} 2$ Intermediates and Reactivity via O-O Cleavage Chemistry. J. Am. Chem. Soc. 2016, 138 (49), 16148-16158.

49. Moenne-Loccoz, P.; Karlin, K. D.; Liu, J. J.; Siegler, M. A., Direct Resonance Raman Characterization of a Peroxynitrito Copper Complex Generated from O2 and NO and Mechanistic Insights into Metal Mediated Peroxynitrite Decomposition. Angew. Chem. Int. Ed. 2019.

50. Sharma, S. K.; Schaefer, A. W.; Lim, H.; Matsumura, H.; Moenne-Loccoz, P.; Hedman, B.; Hodgson, K. O.; Solomon, E. I.; Karlin, K. D., A Six-Coordinate Peroxynitrite Low-Spin Iron (III) Porphyrinate Complex. The Product of the Reaction of Nitrogen Monoxide ( $\cdot$ NO (g)) with a Ferric-Superoxide Species. J. Am. Chem. Soc. 2017, 139 (48), 17421-17430.

51. Caranto, J. D., The emergence of nitric oxide in the biosynthesis of bacterial natural products. Curr. Opin. Chem. Biol. 2019, 49, 130-138.

52. Waldman, A. J.; Ng, T. L.; Wang, P.; Balskus, E. P., Heteroatom-heteroatom bond formation in natural product biosynthesis. Chem. Rev. 2017, 117 (8), 5784-5863.

53. Tan, C. Y.; Hirakawa, H.; Suzuki, R.; Haga, T.; Iwata, F.; Nagamune, T., Immobilization of a bacterial cytochrome P450 monooxygenase system on a solid support. Angew. Chem. 2016, 128 (48), 15226-15230.

54. Reipa, V.; Holden, M.; Mayhew, M. P.; Vilker, V. L., Temperature-induced structural changes in putidaredoxin: a circular dichroism and UV-vis absorption study. Biochim. Biophys. Acta Proteins Proteom. 2004, 1699 (1-2), 229-234.

55. Munro, A. W.; Lindsay, J. G.; Coggins, J. R.; Kelly, S. M.; Price, N. C., NADPH oxidase activity of cytochrome P-450 BM3 and its constituent reductase domain. Biochim Biophys. Acta Bioenerg. 1995, 1231 (3), 255-264. 
56. Boddupalli, S. S.; Estabrook, R. W.; Peterson, J. A., Fatty acid monooxygenation by cytochrome P-450BM-3. J. Biol. Chem. 1990, 265 (8), 4233-4239.

57. Sadeghi, S. J.; Gilardi, G., Chimeric P 450 enzymes: Activity of artificial redox fusions driven by different reductases for biotechnological applications. Biotechnol. Appl. Biochem. 2013, 60 (1), 102-110.

58. Li, Z.; Jiang, Y.; Guengerich, F. P.; Ma, L.; Li, S.; Zhang, W., Engineering cytochrome P450 enzyme systems for biomedical and biotechnological applications. J. Biol. Chem. 2020, 295 (3), 833-849.

59. Lipscomb, J. D.; Sligar, S. G.; Namtvedt, M.; Gunsalus, I., Autooxidation and hydroxylation reactions of oxygenated cytochrome P-450cam. J. Biol. Chem. 1976, 251 (4), 1116-1124.

60. Denisov, I. G.; Grinkova, Y. V.; Baas, B. J.; Sligar, S. G., The ferrous-dioxygen intermediate in human cytochrome P450 3A4 substrate dependence of formation and decay kinetics. J. Biol. Chem. 2006, 281 (33), 23313-23318.

61. Sligar, S.; Debrunner, P.; Lipscomb, J.; Namtvedt, M.; Gunsalus, I., A role of the putidaredoxin $\mathrm{COOH}$-terminus in P-450cam (cytochrome m) hydroxylations. Proc. Natl. Acad. Sci. U.S.A. 1974, 71 (10), 3906-3910.

62. Lipscomb, J. D.; Sligar, S. G.; Namtvedt, M. J.; Gunsalus, I. C., Autooxidation and hydroxylation reactions of oxygenated cytochrome P-450cam. J. Biol. Chem. 1976, 251 (4), 1116-1124.

63. Denisov, I. G.; Makris, T. M.; Sligar, S. G., Cryotrapped reaction intermediates of cytochrome P450 studied by radiolytic reduction with phosphorus-32. J. Biol. Chem. 2001, 276 (15), 11648-11652.

64. Purdy, M. M.; Koo, L. S.; Ortiz de Montellano, P. R.; Klinman, J. P., Mechanism of O2 activation by cytochrome P450cam studied by isotope effects and transient state kinetics. Biochemistry 2006, 45 (51), 15793-15806.

65. Glascock, M. C.; Ballou, D. P.; Dawson, J. H., Direct Observation of a Novel Perturbed Oxyferrous Catalytic Intermediate during Reduced Putidaredoxin-initiated Turnover of Cytochrome P-450-CAM Probing the Effector Rrole of Putidaredoxin in Catalysis. J. Biol. Chem. 2005, 280 (51), 42134-42141.

66. Brewer, C. B.; Peterson, J. A., Single turnover kinetics of the reaction between oxycytochrome P-450cam and reduced putidaredoxin. J. Biol. Chem. 1988, 263 (2), 791-798.

67. Tosha, T.; Yoshioka, S.; Hori, H.; Takahashi, S.; Ishimori, K.; Morishima, I., Molecular mechanism of the electron transfer reaction in cytochrome P450cam- putidaredoxin: Roles of glutamine 360 at the heme proximal site. Biochemistry 2002, 41 (47), 13883-13893.

68. Hanley, S. C.; Ost, T. W.; Daff, S., The unusual redox properties of flavocytochrome P450 BM3 flavodoxin domain. Biochem. Biophys. Res. Commun. 2004, 325 (4), 1418-1423.

69. Imai, M.; Shimada, H.; Watanabe, Y.; Matsushima-Hibiya, Y.; Makino, R.; Koga, H.; Horiuchi, T.; Ishimura, Y., Uncoupling of the cytochrome P-450cam monooxygenase reaction by a single mutation, threonine-252 to alanine or valine: possible role of the hydroxy amino acid in oxygen activation. Proc. Natl. Acad. Sci. U.S.A. 1989, 86 (20), 7823-7827.

70. Martinis, S. A.; Atkins, W. M.; Stayton, P. S.; Sligar, S. G., A conserved residue of cytochrome P-450 is involved in heme-oxygen stability and activation. J. Am. Chem. Soc. 1989, 111 (26), 9252-9253.

71. Gerber, N. C.; Sligar, S. G., A role for Asp-251 in cytochrome P-450cam oxygen activation. J. Biol. Chem. 1994, 269 (6), 4260-4266. 
72. Nagano, S.; Poulos, T. L., Crystallographic Study on the Dioxygen Complex of Wildtype and Mutant Cytochrome P450cam Implications for the Dioxygen Activation Mechanism. $J$. Biol. Chem. 2005, 280 (36), 31659-31663.

73. Schlichting, I.; Berendzen, J.; Chu, K.; Stock, A. M.; Maves, S. A.; Benson, D. E.; Sweet, R. M.; Ringe, D.; Petsko, G. A.; Sligar, S. G., The catalytic pathway of cytochrome P450cam at atomic resolution. Science 2000, 287 (5458), 1615-1622. 


\section{Supplementary information}
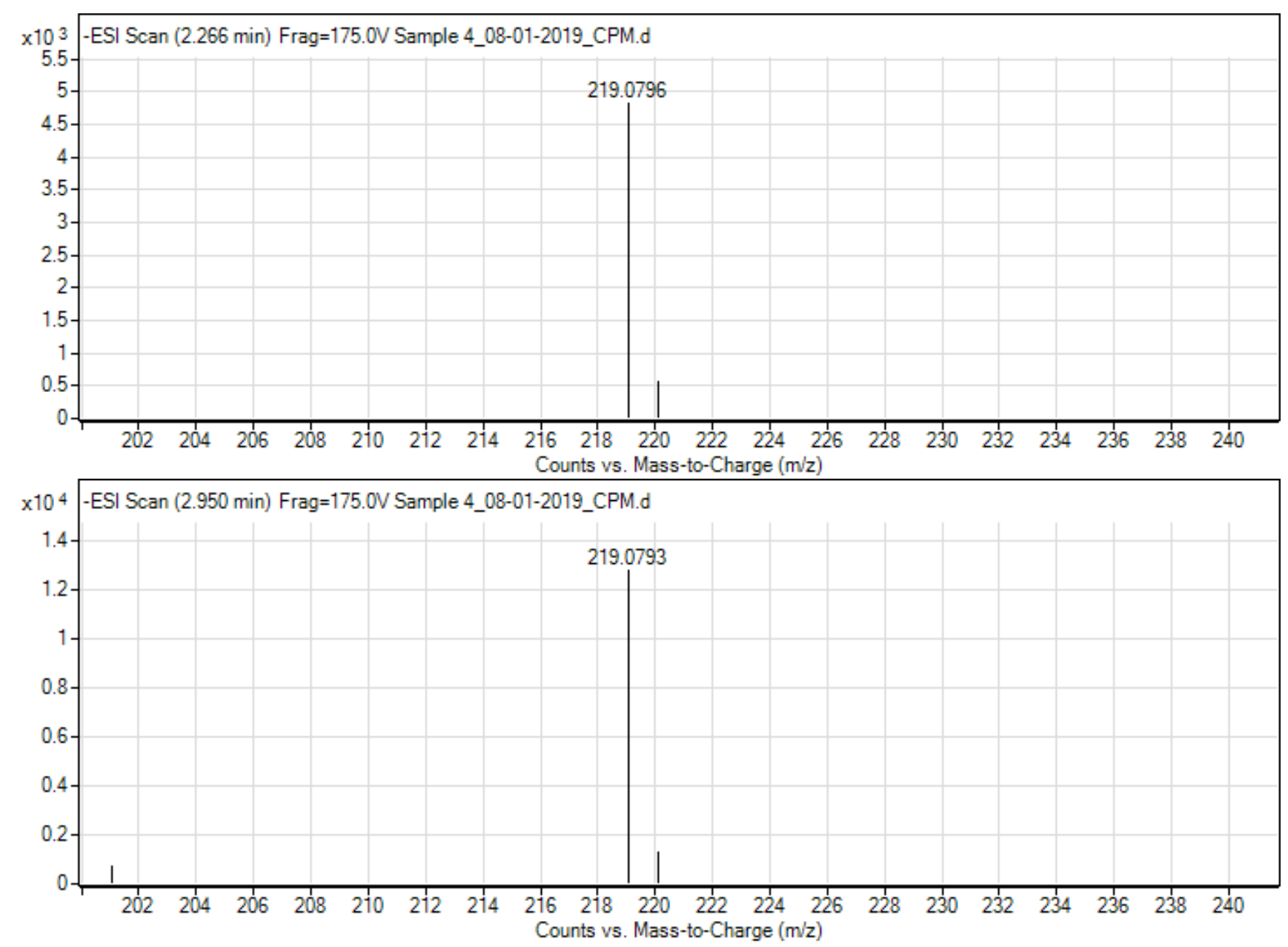

Figure S1 - MS spectra of peaks eluted at 2.3 and 3.0 minutes resulting from LC separation of TB14 peroxide shunt sample shown in cyan trace of Figure 2 in the main text. 


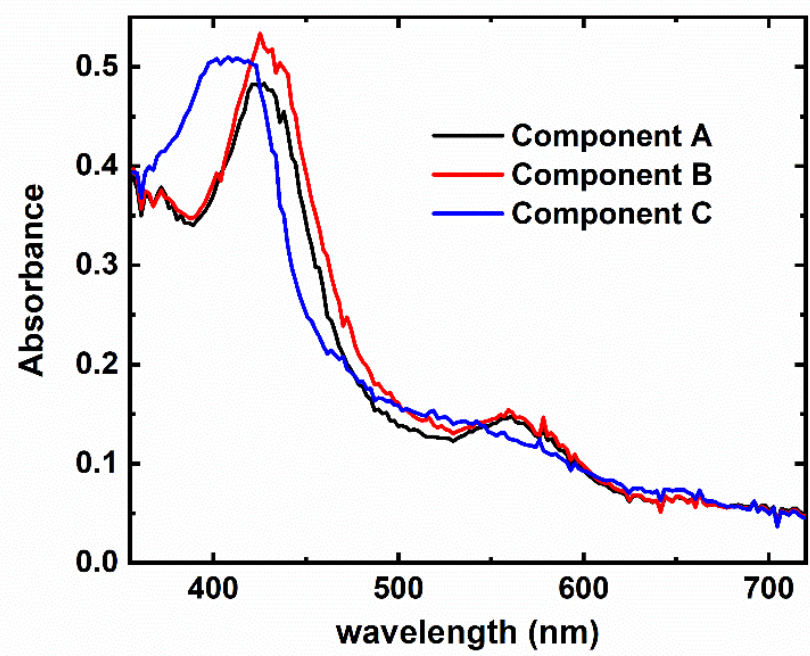

Figure S2. Representative component spectra obtained from global fitting of stopped-flow data of Fe(II) TxtE $+\mathrm{PdX}$ red vs. $\mathrm{O}_{2}$ reaction. Stopped-flow time course shown in Figs. 4A and $\mathrm{B}$ was fit to a two-step model $(\mathrm{A} \rightarrow \mathrm{B} \rightarrow \mathrm{C})$ with $k_{1}=$ $0.03 \mathrm{~s}^{-1}$ and $k_{2}=0.006 \mathrm{~s}^{-1}$.
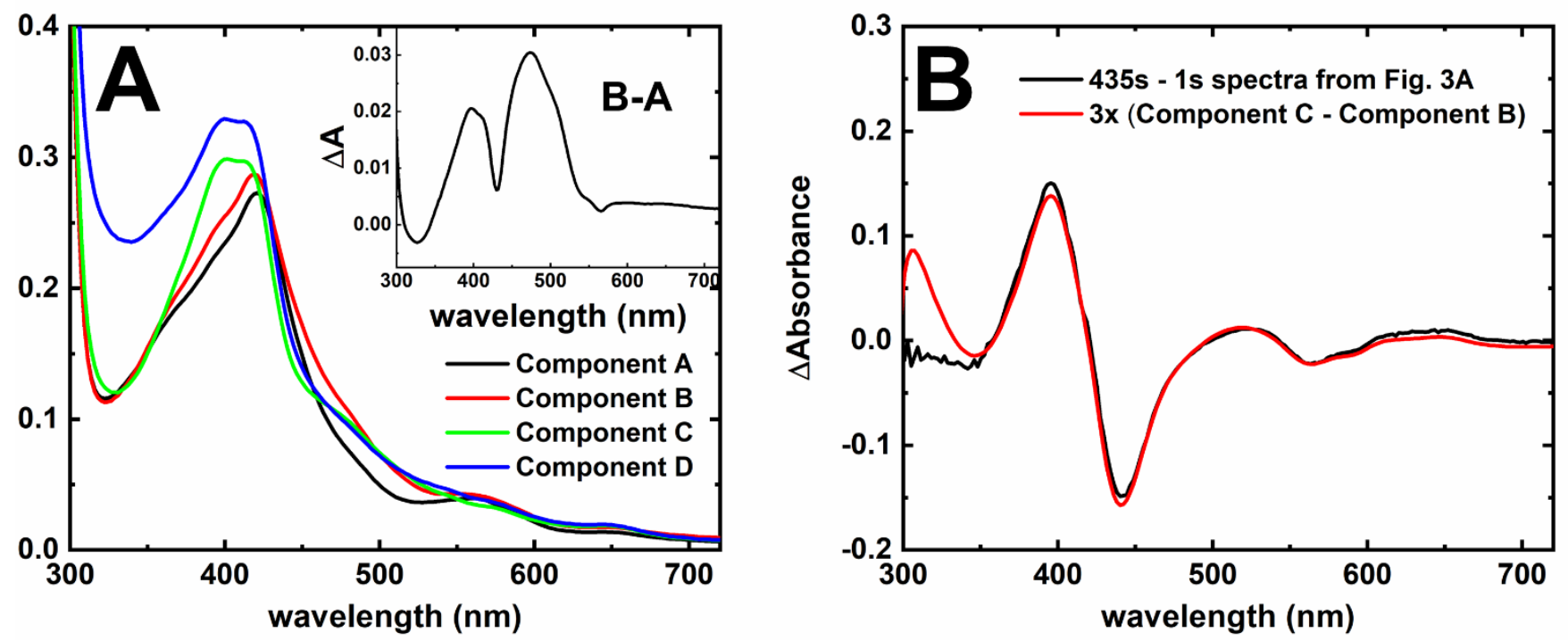

Figure S3. Component spectra (A) and difference spectra (B) resulting from global analysis of TB144e-red Vs. $\mathrm{O}_{2}$ stoppedflow data. Stopped-flow time course shown in Figs. 4C and D was fit to a three-step model $(\mathrm{A} \rightarrow \mathrm{B} \rightarrow \mathrm{C} \rightarrow \mathrm{D})$ with $k_{1}=$ $0.2 \mathrm{~s}^{-1}, k_{2}=0.01 \mathrm{~s}^{-1}$, and $k_{3}=0.004 \mathrm{~s}^{-1}$. Inset shows difference spectra of component B minus component A. 


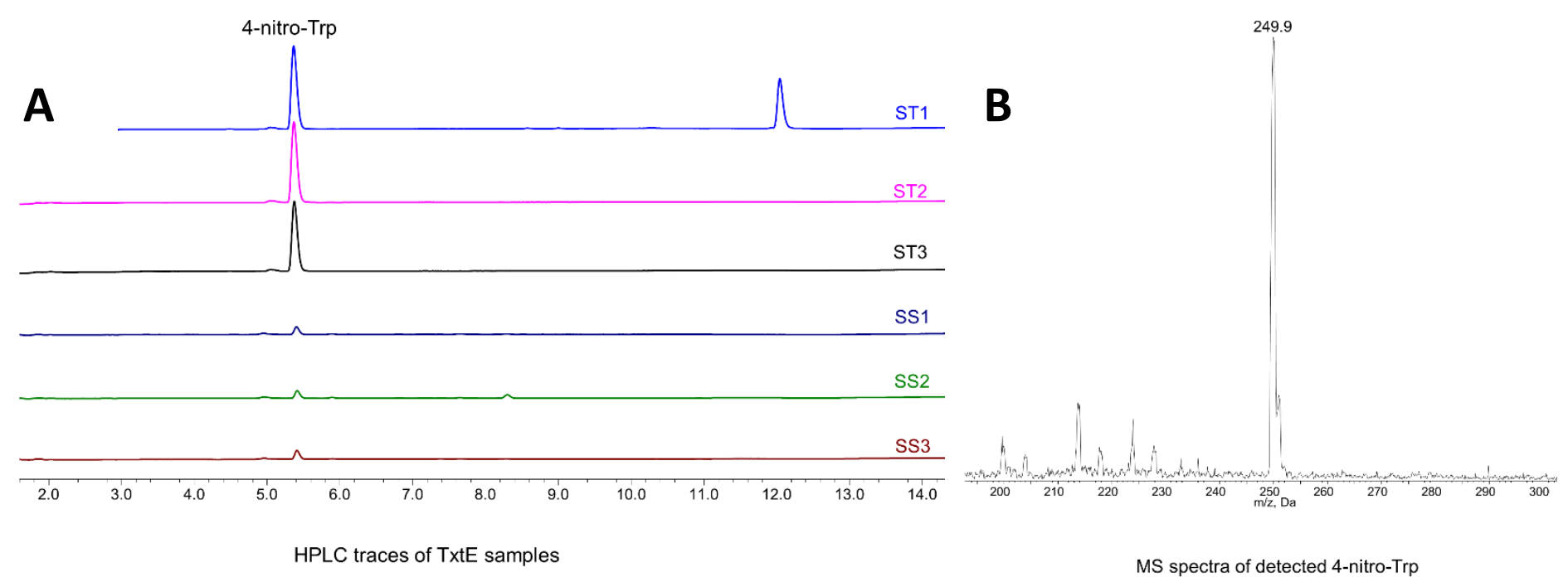

Figure S4. A) HPLC traces of single turnover TxtE (ST) and steady state TB14 (SS) replicates monitoring 380-nm absorbance of 4-NO $\mathrm{N}_{2}$-L-Trp. B) MS spectrum of 5.5 min elution peak. Reaction conditions: $100 \mu \mathrm{M}$ FeII TxtE, $500 \mu \mathrm{M}$ LTrp, 0.86 mM PROLI-NONOate in pH 8.0 buffer (ST); $0.5 \mu \mathrm{M}$ TB14, $500 \mu \mathrm{M}$ L-Trp, $2 \mathrm{mM}$ NADPH, and $1.33 \mathrm{mM}$ DEA- NONOate ( 2 mM NO) in pH 8.0 buffer (SS).

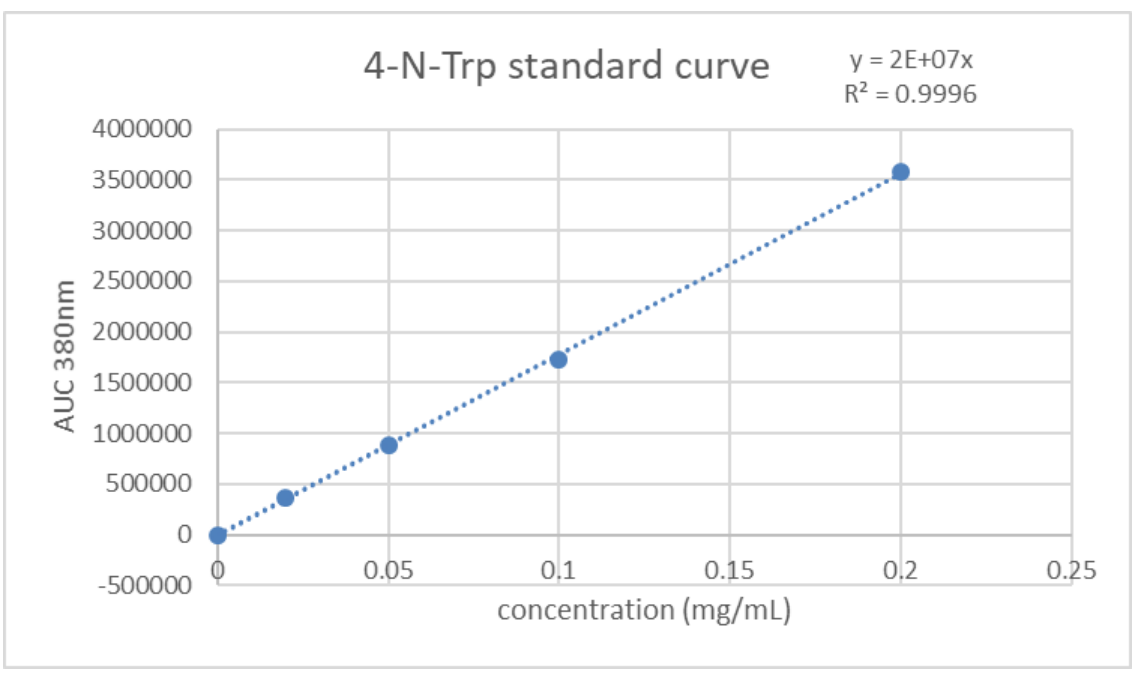

Figure S5. Calibration curve for 4- $\mathrm{NO}_{2}$-L-Trp standard. AUC = area-under-curve. 


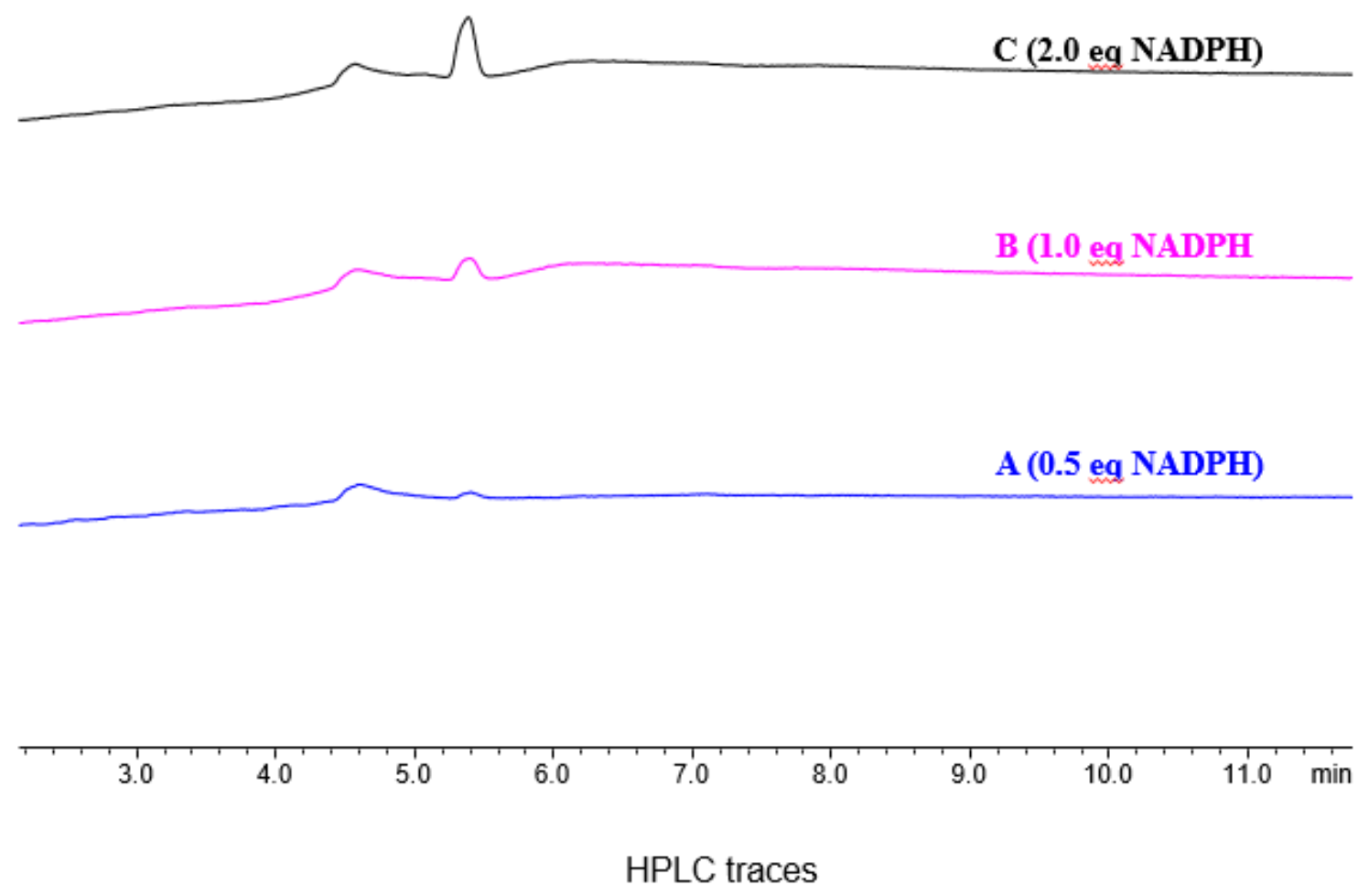

Figure S6. Representative HPLC traces of single nitration turnover TB14 samples containing 0.5 eq (A), 1.0 eq (B), or 2.0 eq NADPH monitoring 380-nm absorbance of 4-NO2-L-Trp. Reaction conditions: $20 \mu \mathrm{M}$ TB14, $0.5 \mathrm{mM}$ L-Trp, and 1 mM PROLI-NONOate ( 2 mM NO equivalent) with $10 \mu \mathrm{M}$ (A), $20 \mu \mathrm{M}$ (B), or $40 \mu \mathrm{M}$ (C) NADPH.

Table S1. AUC of 380-nm elution peaks for all samples HPLC samples in Fig. S4 of ST and SS samples and calculated [4- $\left.\mathrm{NO}_{2}-\mathrm{L}-\mathrm{Trp}\right]$ based on standard curve for each sample.

\section{Sample}

ST1

ST2

ST3

SS1

SS2

SS3
AUC (380nm)

335557

323518

271855

26407

26337

30424

\section{Calculated}

Concentration (mg/mL) Concentration ( $\mu \mathrm{M})$

0.0189

0.0182

0.0153

0.0015

0.0015

0.0017
75.6896

72.9741

61.3208

5.9565

5.9407

6.8626 
Table S2. AUC of 380-nm elution peaks for all samples HPLC samples in Fig. S6 of TB14 single-turnover samples with varying NADPH concentration.

\section{AUC (380 nm)}

\begin{tabular}{|c|c|c|c|c|c|c|}
\hline Sample & Trial 1 & Trial 2 & Trial 3 & average & $\begin{array}{l}{\left[4-\mathrm{NO}_{2}-\mathrm{L}-\mathrm{Trp}\right]} \\
(\mathrm{mg} / \mathrm{mL})\end{array}$ & {$\left[4-\mathrm{NO}_{2}-\mathrm{L}-\mathrm{Trp}\right](\mu \mathrm{M})$} \\
\hline$X$ & 2557 & 2531 & 2693 & 2593 (87) & 0.000145803 & $0.58(0.02)$ \\
\hline $\mathrm{Y}$ & 8921 & 8679 & 14711 & $\begin{array}{l}10770 \\
(3414)\end{array}$ & 0.000605455 & $2.4(0.8)$ \\
\hline Z & 25084 & 19003 & 18965 & $\begin{array}{l}21017 \\
(3521\end{array}$ & 0.001181492 & $4.7(0.8)$ \\
\hline
\end{tabular}

